\title{
Impaired thymic tolerance to $\alpha$-myosin directs autoimmunity to the heart in mice and humans
}

\author{
HuiJuan Lv, ${ }^{1,2,3}$ Evis Havari, ${ }^{1}$ Sheena Pinto, ${ }^{4}$ Raju V.S.R.K. Gottumukkala, ${ }^{1,2,3}$ Lizbeth Cornivelli, ${ }^{1}$ \\ Khadir Raddassi, 3,5 Takashi Matsui, 3,6 Anthony Rosenzweig, 3,6 Roderick T. Bronson, ${ }^{3}$ \\ Ross Smith, ${ }^{1}$ Anne L. Fletcher, ${ }^{3,7}$ Shannon J. Turley, ${ }^{3,7}$ Kai Wucherpfennig, ${ }^{3,7}$ \\ Bruno Kyewski, ${ }^{4}$ and Myra A. Lipes ${ }^{1,2,3}$
}

\begin{abstract}
${ }^{1} J o s l i n$ Diabetes Center, Boston, Massachusetts, USA. ²Department of Medicine, Brigham and Women's Hospital, Boston, Massachusetts, USA. ${ }^{3}$ Harvard Medical School, Boston, Massachusetts, USA. ${ }^{4}$ German Cancer Research Center, Heidelberg, Germany. ${ }^{5}$ Center for Neurologic Diseases, Brigham and Women's Hospital, Boston, Massachusetts, USA. ${ }^{6}$ The Cardiovascular Institute, Beth Israel Deaconess Medical Center, Boston, Massachusetts, USA. ${ }^{7}$ Dana-Farber Cancer Institute, Boston, Massachusetts, USA.
\end{abstract}

\begin{abstract}
Autoimmunity has long been linked to myocarditis and its sequela, dilated cardiomyopathy, the leading causes of heart failure in young patients. However, the underlying mechanisms are poorly defined, with most clinical investigations focused on humoral autoimmunity as the target for intervention. Here, we show that the $\alpha$-isoform of myosin heavy chain ( $\alpha$-MyHC, which is encoded by the gene Myb6) is the pathogenic autoantigen for $\mathrm{CD}^{+} \mathrm{T}$ cells in a spontaneous mouse model of myocarditis. Further, we found that $M y b 6$ transcripts were absent in mouse medullary thymic epithelial cells (mTECs) and peripheral lymphoid stromal cells, which have been implicated in mediating central and peripheral $\mathrm{T}$ cell tolerance, respectively. Transgenic expression of $\alpha-\mathrm{MyHC}$ in thymic epithelium conferred tolerance to cardiac myosin and prevented myocarditis, demonstrating that $\alpha-\mathrm{MyHC}$ is a primary autoantigen in this disease process. Remarkably, we found that humans also lacked $\alpha-\mathrm{MyHC}$ in mTECs and had high frequencies of $\alpha$-MyHC-specific $\mathrm{T}$ cells in peripheral blood, with markedly augmented T cell responses to $\alpha-\mathrm{MyHC}$ in patients with myocarditis. Since $\alpha-\mathrm{MyHC}$ constitutes a small fraction of $\mathrm{MyHC}$ in human heart, these findings challenge the longstanding notion that autoimmune targeting of $\mathrm{MyHC}$ is due to its cardiac abundance and instead suggest that it is targeted as a result of impaired $T$ cell tolerance mechanisms. These results thus support a role for $T$ cell-specific therapies for myocarditis.
\end{abstract}

\section{Introduction}

Myocarditis is a major cause of heart disease in young patients and a common precursor of heart failure due to dilated cardiomyopathy (1-3). The prognosis for dilated cardiomyopathy is poor, with approximately $40 \%$ patients either dying of this condition or requiring heart transplantation, a percentage that has remained unchanged despite decades of advancements in cardiovascular therapeutics (4). Persistent autoimmune responses have been postulated to underlie the progression from myocarditis to dilated cardiomyopathy, and patients often develop autoantibodies to cardiac proteins. However, the role of autoantibodies in the pathogenesis of human dilated cardiomyopathy is unclear. Although strong evidence suggests that myocarditis is T cell-mediated in mouse models (5-8), there is a paucity of information about the specificity and role of T cells in human disease (9).

Myocarditis has long been linked to viral infection, most notably coxsackievirus B3. Affected patients and coxsackie B3-infected mice develop autoantibodies to several cardiac antigens, the most prominent of which is myosin heavy chain (MyHC) (10). Similar autoantibody responses have been observed in patients following myocardial infarction and other forms of cardiac injury (3). These findings have supported the notion that the anti-myosin responses in myocarditis are induced not by the viruses themselves

Authorship note: Evis Havari and Sheena Pinto are co-second authors. Conflict of interest: The authors have declared that no conflict of interest exists. Citation for this article: J Clin Invest. 2011;121(4):1561-1573. doi:10.1172/JCI44583. ("molecular mimicry") but by endogenous antigens released during virus-mediated cardiac damage $(5,11)$. However, it has been argued that necrotic release of intracellular self antigens should not trigger adaptive immune responses because $T$ cells specific for these antigens would normally be eliminated during negative selection in the thymus, a primary barrier against autoimmunity.

The heart expresses two closely related (93\% amino acid sequence identity) isoforms of $\mathrm{MyHC}$ : $\alpha-\mathrm{MyHC}$, which is expressed exclusively in cardiac muscle, and $\beta-\mathrm{MyHC}$, which is also expressed in skeletal muscle (ref. 12 and Figure 1A). Immunization with cardiac myosin, but not skeletal myosin, results in $\mathrm{CD}^{+} \mathrm{T}$ cell-mediated myocarditis $(5,6)$, and the pathogenic epitopes of cardiac myosin localize to sequences that are unique to $\alpha-\operatorname{MyHC}(13,14)$. The dominant role of $\alpha-\mathrm{MyHC}$ as an autoantigen in experimental myocarditis has been attributed to its cardiac-specific expression and abundance in rodent heart (15). However, the basis for the enhanced immunogenicity of peptides unique to $\alpha-\mathrm{MyHC}$ has not been defined. Moreover, the relevance of these findings to humans, in whom $\beta$-MyHC is the major isoform expressed in heart, is unclear.

Although viruses are considered an important etiological agent of myocarditis, the cause of disease in any given patient often remains unknown (16). Alternatively, it has been postulated that some forms of human myocarditis are of primary autoimmune etiology. In support of this possibility are studies showing that patients with myocarditis and no evidence of viral genome in the myocardium benefit from immunosuppression (17). We have reported that transgenic NOD mice that express the human MHC class II mol- 
A

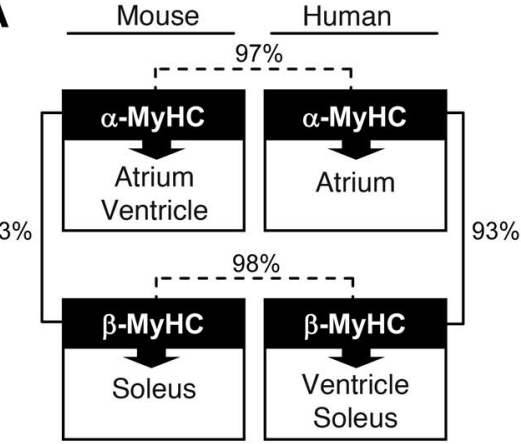

C

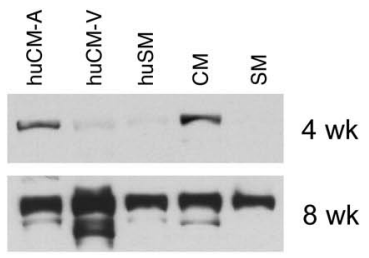

B

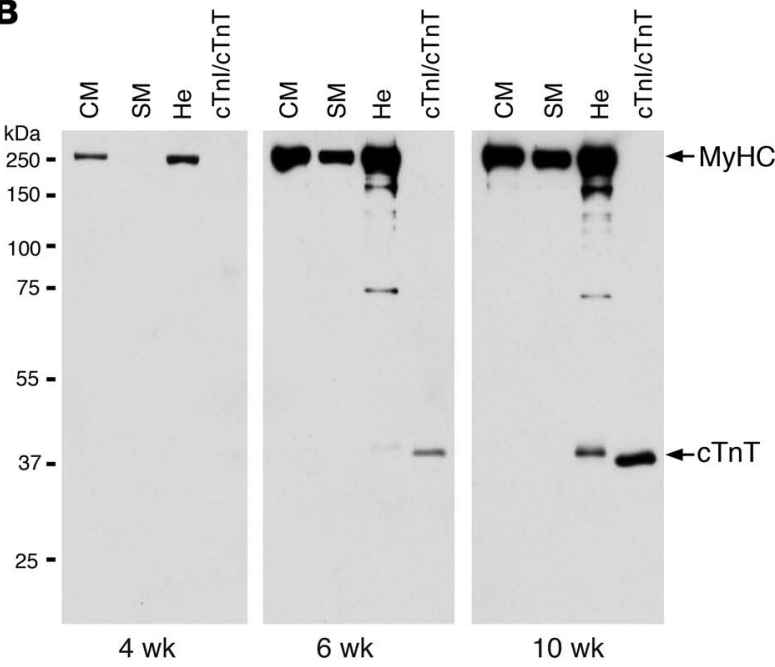

\section{Figure 1}

Intra- and intermolecular spreading of humoral autoimmunity from regions unique to cardiac-specific $\alpha$-MyHC in longitudinal serum samples from individual DQ8+NOD mice. (A) Schematic of the percent amino acid sequence identity between the different MyHC isoforms (dashed and solid lines) and their predominant site of expression (solid arrows) in mice and humans. (B) Western blots with $0.25 \mu \mathrm{g} / \mathrm{lane}$ each of purified mouse cardiac myosin (CM) and soleus myosin (SM), $1 \mu \mathrm{g}$ total mouse heart myofibrillar extracts (He), and $0.25 \mu \mathrm{g}$ purified mouse cardiac troponin I and cardiac troponin T (cTnl/cTnT) were probed with serial sera from the same DQ8+NOD mouse at ages 4, 6, and 10 weeks. The positions of MyHC and cTnT are indicated. Shown is a representative result of independent experiments from 4 different mice. (C) Western blots with $0.25 \mu \mathrm{g} / \mathrm{lane}$ each of purified huCM-A, huCM-V, huSM, mouse cardiac, and soleus myosin were probed with sera from a DQ8+NOD mouse at ages 4 and 8 weeks.

ecule DQ8, instead of the mouse MHC class II molecule I-Ag7 (hereafter, DQ8 ${ }^{+}$NOD mice), spontaneously develop autoimmune myocarditis with high-titer autoantibodies to $\mathrm{MyHC}$ and premature death due to heart failure, resembling human myocarditis $(7,8)$. Since myocarditis in DQ8 ${ }^{+}$NOD mice did not require microbial or pathological injury triggers, this model prompted a reexamination of the mechanisms by which cardiac self tolerance is broken.

Here we show that $\alpha$-MyHC is the pathogenic autoantigen for $\mathrm{CD}^{+} \mathrm{T}$ cells in spontaneous myocarditis. We demonstrate that transcripts for $\alpha-\mathrm{MyHC}$ are absent in mouse thymic medullary epithelial cells (mTECs), which play a crucial role in the maintenance of self tolerance and prevention of autoimmunity (18). We further show that transgenic expression of $\alpha$-MyHC in thymus induced tolerance to cardiac myosin and prevented myocarditis. Remarkably, humans also lack expression of $\alpha$-MyHC in mTECs, and patients with myocarditis show markedly elevated frequencies of $\alpha$-MyHC-specific T cells in peripheral blood. Our studies indicate that impaired central tolerance to $\alpha-\mathrm{MyHC}$ contributes to the pathogenesis of myocarditis in both mice and humans. These findings have diagnostic and therapeutic implications, and support a role for $\mathrm{T}$ cell-targeted therapies for this serious disease.

\section{Results}

Spontaneous myocarditis is initiated by immune responses directed against $\alpha-M y H C$. To investigate the earliest responses in myocarditis, we analyzed serial serum samples from the same DQ8 ${ }^{+}$NOD mice, beginning at approximately 4 weeks of age, by immunoblotting for IgG reactivity against a panel of mouse antigens that included cardiac myosin (Figure 1B) purified from adult heart (in which $>90 \%$ of the total MyHC protein is $\alpha$-MyHC; refs. 12, 19); skeletal myosin from hind limb soleus muscle, which does not contain $\alpha-\mathrm{MyHC}$ but in which greater than $90 \%$ fibers express $\beta$-MyHC (20); whole heart lysates, cardiac troponin I; and cardiac troponin $\mathrm{T}$ (Figure 1B). Cardiac myosin and soleus myosin were prepared side-by-side using the identical purification protocols (ref. 8 and Supplemental Figure 2; supplemental material available online with this article; doi:10.1172/JCI44583DS1). We found that autoantibodies initially reacted only with cardiac myosin, but then, by 6 weeks of age, autoreactivity spread to both cardiac and skeletal myosin (Figure 1B). Subsequently, the autoantibodies targeted cardiac troponin $\mathrm{T}$, and later cardiac troponin I (data not shown). These findings suggested that tolerance was initially lost to epitopes unique to the cardiac-specific $\alpha$-isoform of MyHC, with the subsequent development of skeletal myosin-cross-reactive antibodies representing intramolecular epitope spreading to residues of $\alpha$-MyHC shared with $\beta$-MyHC that is also expressed in soleus muscle, and finally, intermolecular spreading to other cardiac proteins.

To further confirm the isoform specificity of autoantibody recognition, we examined serial serum reactivity against cardiac myosins that varied in the relative amount of $\alpha$ - and $\beta$-MyHC expressed. Although $\alpha$ - and $\beta$-MyHC proteins are highly conserved between humans and mice (Figure 1A and Supplemental Figure 1), $\beta-\mathrm{MyHC}$ is the dominant isoform expressed in adult human ventricle, constituting greater than $90 \%$ of the total $\mathrm{MyHC}$ protein (21), whereas $\alpha-\mathrm{MyHC}$ is the dominant isoform expressed in human atria (ref. 22 and Figure 1A). We found that serum from 4-week-old DQ8 ${ }^{+}$NOD mice initially recognized human atrial cardiac myosin (huCM-A, Figure 1C) and mouse cardiac myosin, but by 8 weeks, the reactivities diversified to include human ventricle cardiac myosin (huCM-V), human soleus myosin, and mouse sole- 
A

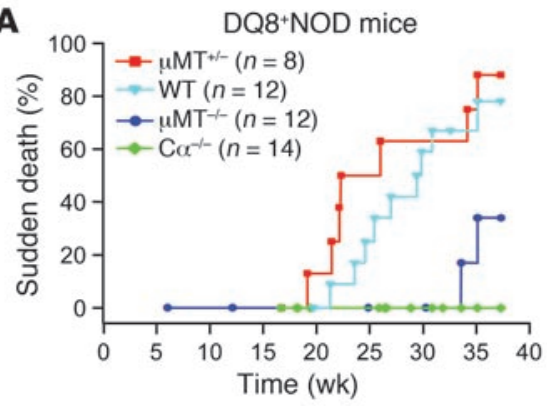

B
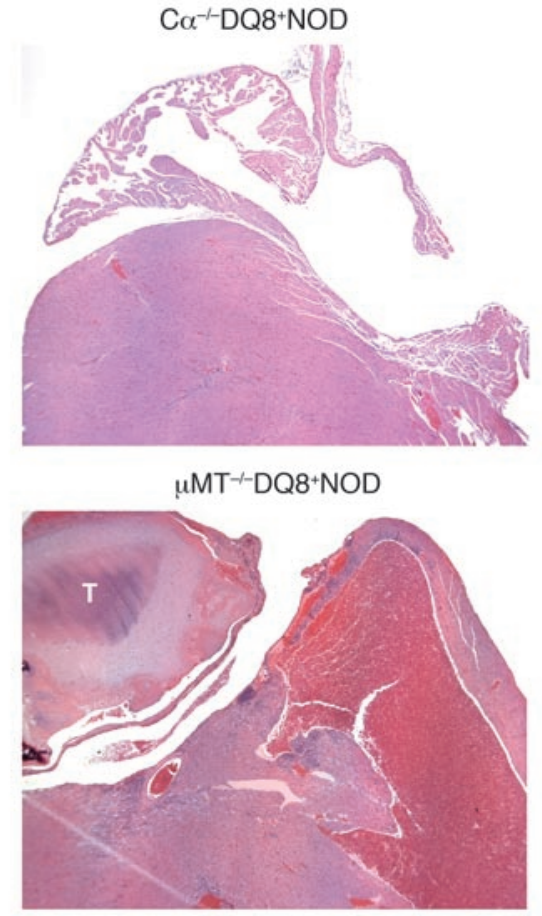

us myosin. Taken together, these findings showed that there was a hierarchy in the loss of humoral tolerance to cardiac autoantigens in spontaneous myocarditis, with the earliest responses focused on epitopes unique to $\alpha$-MyHC.

Myocarditis develops in the absence of a bumoral immune response. The early appearance of high-titer skeletal myosin-reactive autoantibodies contrasted with cardiac specificity of myocarditis, but was consistent with previous adoptive transfer studies showing that autoantibodies alone do not induce myocarditis $(7,8)$. To further investigate the relative importance of $\mathrm{T}$ and $\mathrm{B}$ cells in disease initiation, we generated DQ8 ${ }^{+} \mathrm{NOD}$ mice lacking either $\alpha \beta \mathrm{T}$ cells $\left(\mathrm{C} \alpha^{-/}\right)$ or B cells $\left(\mu \mathrm{MT}^{-/}\right)$and followed them for myocarditis until 37 weeks. In the absence of $\mathrm{T}$ cells, $\mathrm{C}^{-/-} \mathrm{DQ} 8^{+} \mathrm{NOD}$ mice were completely protected from myocarditis, with $100 \%$ survival $(n=14$, $P<0.001$ compared with DQ8 ${ }^{+}$NOD mice; Figure $2 \mathrm{~A}$ ) and no evidence of cardiac infiltration (Figure $2 \mathrm{~B}$ ), a phenotype resembling the complete myocarditis protection we observed in $\mathrm{T}$ and B cell-deficient DQ8 ${ }^{+} \mathrm{Rag}^{-1}$-NOD mice (8). In addition, none of the $\mathrm{C}^{-/-} \mathrm{DQ}^{+} \mathrm{NOD}$ mice developed autoantibodies to cardiac myosin ( 0 of 14 female mice at 37 weeks), confirming that production of these IgG autoantibodies is $\mathrm{CD} 4^{+} \mathrm{T}$ cell dependent. In contrast, B cell-deficient $\mu \mathrm{MT}^{-/-} \mathrm{-DQ} 8^{+} \mathrm{NOD}$ mice developed myocarditis with lymphocytic infiltrates and cardiac thrombosis

\section{Figure 2}

Mortality from myocarditis in DQ8+NOD mice (WT) in the absence of $B$ cells or T cells. (A) Kaplan-Meier survival curves of female DQ8+NOD $\mu \mathrm{MT}^{+/-}, \mathrm{WT}, \mu \mathrm{MT}^{-/-}$, and $\mathrm{C}^{-/-}$mice followed through 37 weeks of age. The mortality from myocarditis did not differ statistically between DQ8 ${ }^{+}$NOD WT and $\mu \mathrm{MT}^{+/-}$mice but was significant $(P<0.001)$ in all other comparisons. (B) Heart histology shows the absence of infiltrates in $\mathrm{C}^{-1-D Q 8}{ }^{+} \mathrm{NOD}$ mice and severe lymphocytic infiltrates and cardiac thrombosis $(\mathrm{T})$ in $\mu \mathrm{MT}^{-1-} \mathrm{DQ8}{ }^{+} \mathrm{NOD}$ mice. Original magnification, $\times 37.5$.

(Figure 2B). However, $\mu \mathrm{MT}^{-} /-\mathrm{DQ} 8^{+}$mice displayed better survival than B cell-sufficient $\mu \mathrm{MT}^{+/}$-DQ8 $8^{+}$littermates $(P<0.001$; Figure $2 \mathrm{~A})$. These findings show that although the initiation of myocarditis is $\mathrm{T}$ cell dependent, $\mathrm{B}$ cells also play an important role in disease progression, as has been observed in other $\mathrm{T}$ cell-mediated autoimmune diseases (23).

$C D 4^{+} T$ cell clones and bulk T cells isolated from advanced myocarditis lesions specifically recognize $\alpha-M y H C$. In view of the essential role of $\mathrm{T}$ cells and MHC class II molecules in spontaneous myocarditis and evidence that $\mathrm{CD} 4^{+} \mathrm{T}$ cells alone can transfer disease (24), we next sought to identify the autoantigenic target(s) of pathogenic $\mathrm{CD} 4^{+} \mathrm{T}$ cells. To achieve this, we isolated $\mathrm{CD} 4^{+} \mathrm{T}$ cell clones directly from myocarditis lesions of a 12 -week-old female DQ8+NOD mouse with high-titer myosin autoantibodies $(>1: 6,400)$ and cardiomegaly at autopsy, using a modification of the Langendorff perfusion procedure in combination with flow cytometry and single-cell sorting (Figure 3A). To limit potential in vitro antigen-driven selection biases, $\mathrm{T}$ cell clones were expanded and restimulated using concanavalin $\mathrm{A}(\mathrm{ConA})$ as a mitogen instead of target organ- or antigen-laden APCs. After several rounds of restimulation, 5 clones were generated, but only two (clone $\mathrm{E}$ and clone 2) grew sufficiently well for subsequent testing. Both clones responded to cardiac myocytes and showed strong dose-dependent proliferative responses to cardiac myosin (Figure 3B) but not soleus myosin. Since clone E showed better growth in culture, it was chosen for further characterization.

Enzyme-linked immunosorbent spot (ELISPOT) analyses revealed that clone E produced large amounts of IFN- $\gamma$, but no IL-4, in response to stimulation with cardiac myosin (Figure 3C), consistent with a Th1 phenotype. In contrast, no cytokines were produced in response to soleus myosin, consistent with the lack of responses in T cell proliferation assays (Figure 3B). Clone E also mounted strong responses to huCM-A, suggesting that the epitope within $\alpha-\mathrm{MyHC}$ was conserved across species (Figure 3D). Of note, clone $\mathrm{E}$ recognized cardiac myosin only when presented on $\mathrm{DQ8}^{+}$ APCs but not on APCs expressing I-Ag7 (WT NOD) (Figure 3E).

Further studies revealed that bulk $\mathrm{T}$ cells isolated from the hearts, cardiac draining lymph nodes, and spleens of DQ8 ${ }^{+} \mathrm{NOD}$ mice predominantly recognized $\alpha$ - but not $\beta$-MyHC (Figure $3 \mathrm{~F}$ and Supplemental Figure 3). Analysis of the cytokine profiles of bulk CD4 ${ }^{+}$ T cells isolated from myocarditis lesions using intracellular cytokine staining for IFN- $\gamma$, TNF- $\alpha$, IL-4, and IL-17 confirmed that the majority of cardiac-infiltrating cells predominantly secreted IFN- $\gamma$ and TNF- $\alpha$, with fewer cells producing IL-4 and very low frequencies or absence of IL-17-producing cells, which were not unmasked by incubation with PMA and ionomycin. Th1 effector responses dominated at all stages of disease progression, although increased frequencies of IL-4-producing cells were observed with advanced disease (Supplemental Figure 4). Thus, the Th1 phenotype of clone E was representative of the majority of heart-infiltrating $\mathrm{T}$ cells. 
A

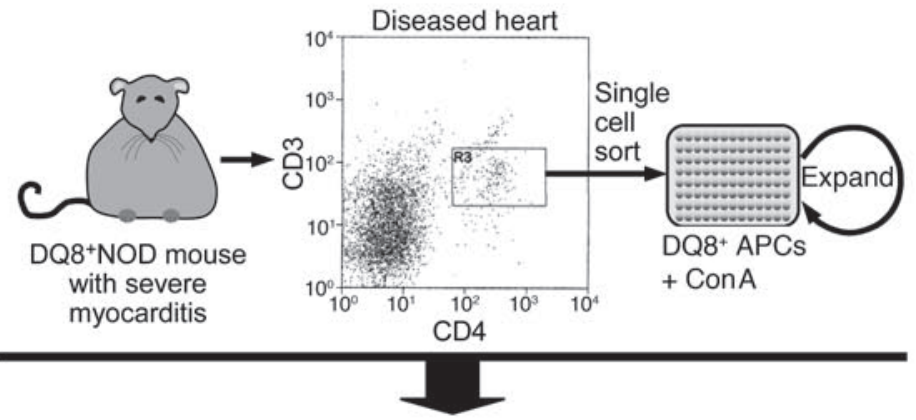

B
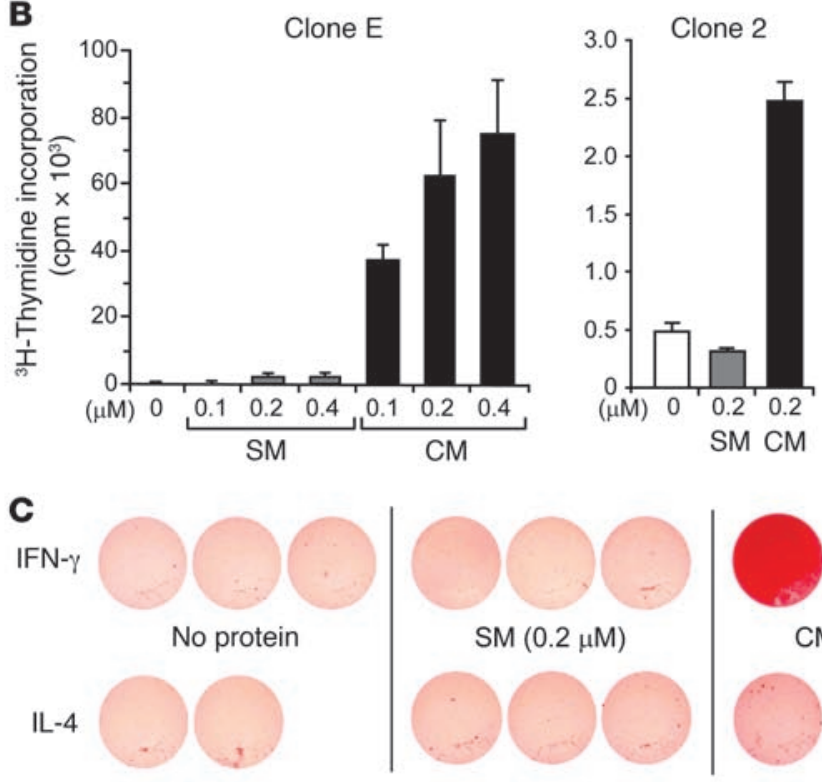

D

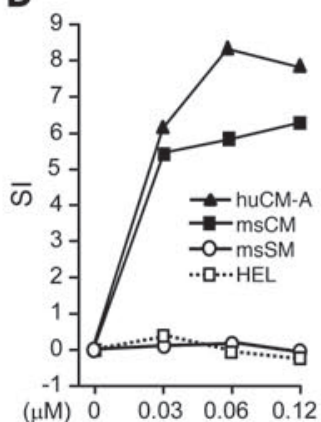

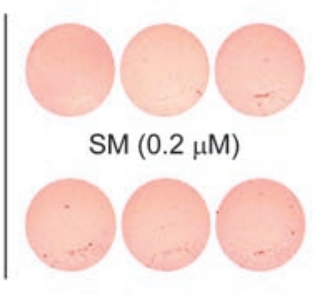

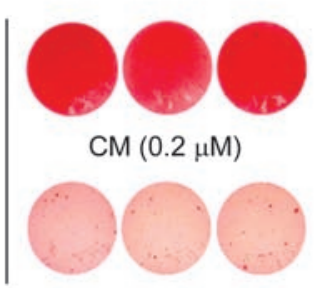

E
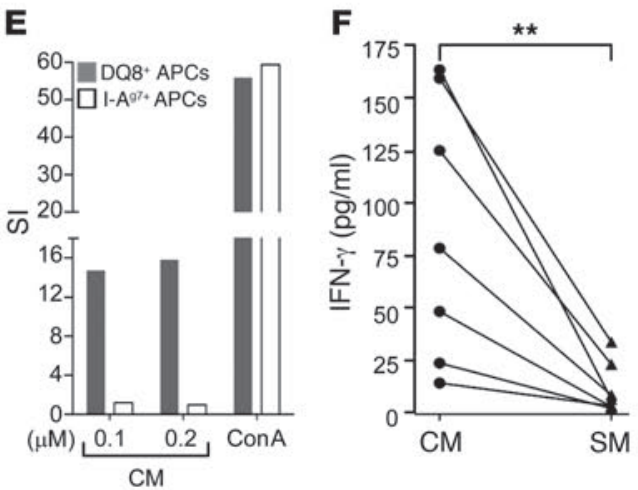

\section{Figure 3}

The generation and characterization of $\mathrm{CD} 4^{+} \mathrm{T}$ cell clones isolated directly from myocarditis lesions of DQ8+NOD mice. (A) The schema shows the protocol of establishing $\mathrm{CD} 4^{+} \mathrm{T}$ cell clones from the myocarditic hearts. (B) Proliferation assay indicates that both clone $\mathrm{E}$ and clone 2 recognize cardiac myosin but not soleus myosin. Data are presented as mean \pm SD. (C) ELISPOT assay shows that clone E produces IFN- $\gamma$ but not IL-4 in response to cardiac myosin, with no responses to soleus myosin. (D) Clone $\mathrm{E}$ also recognizes huCM-A in proliferation assays. SI, stimulation index. (E) Clone $E$ responds to cardiac myosin only in the context of DQ8 ${ }^{+}$APCs and not NOD WT (I-A $\left.{ }^{97}\right)$ APCs. (F) Comparison of IFN- $\gamma$ ELISA responses of splenic $T$ cells to cardiac and soleus myosin in individual DQ8+NOD mice $(n=7)$ with antibody titers ranging from $1: 100$ to $1: 6,400$. Shown is the mean value of duplicate wells for each analysis $\left({ }^{* *} P<0.01\right)$.

cle (Figure 4B), consistent with the cardiac specificity of this clone in vitro (Figure 3, B and C). A separate transfer of $1.5 \times 10^{7}$ clone $\mathrm{E}$ cells yielded identical results. Thus, adoptive transfer of clone $\mathrm{E}$ induced a pathological process that closely recapitulated the original disease process $(7,8)$. Taken together, these data demonstrated that spontaneous myocarditis is mediated by $\alpha-\mathrm{MyHC}$-specific $\mathrm{CD}^{+}$Th 1 cells.

Lack of expression of $\alpha-M y H C$ in both thymus and peripheral lymphoid organs. Although spontaneous islet-specific $\mathrm{T}$ cell responses are difficult to detect in humans and NOD mice, even in the setting of overt diabetes $(26,27)$, we readily detected robust spontaneous cardiac myosin-specific $\mathrm{T}$ cell responses in splenocytes and cardiac draining lymph nodes of DQ8 ${ }^{+} \mathrm{NOD}$ mice, even in mice at the earliest stages of disease (Figure 3F). This suggested that cardiac myosin-specific $\mathrm{T}$ cells are present at a high frequency in the periphery.

Cardiac myosin is a dominant autoantigen in a diversity of other autoimmune heart conditions, including coxsackievirus B myocarditis, Chagas disease, heart rejection, post-commissurotomy, and post-myocardial infarction syndromes (3). This raised the question as to why cardiac myosin should be so highly predisposed to serve as an autoantigen. It has been suggested that tolerance might be less efficient to $\alpha$-MyHC because it is a "late" self anti-

$\alpha-M y H C-$ specific $C D 4^{+} T$ cell clones adoptively transfer myocarditis into immunodeficient recipients. We next tested the pathogenicity of clone $\mathrm{E}$ by adoptive transfer into lymphocyte-deficient $\mathrm{DQ} 8^{+} \mathrm{Rag}^{-/-\mathrm{NOD}}$ recipients (8). Histological examination of the recipient hearts 21 days after injection of $2 \times 10^{7}$ clone E cells revealed severe myocarditis, with diffuse lymphocytic infiltration and myocyte destruction in the atria and more focal involvement of the ventricles (Figure 4A). In addition, lymphocytic infiltrates were observed in the lung around the atrial-derived layers of cardiac muscle surrounding the pulmonary veins (pulmonary myocardium; Figure 4D, arrow), which is the first site of mononuclear cell (MNC) infiltration in spontaneous myocarditis (7) and expresses only $\alpha$-but not $\beta$-MyHC (25). Importantly, infiltrates were absent in skeletal mus- gen that is not fully expressed in heart until several weeks after birth, whereas $\beta$-MyHC is abundantly expressed during fetal life and the early postnatal period (12), when the bulk of the $\mathrm{T}$ cell repertoire is generated.

It is now widely recognized that the thymus, specifically mTECs, plays a crucial role in self-tolerance and prevention of organ-specific autoimmune disease by virtue of its ability to express a wide range of antigens previously considered to be expressed exclusively in peripheral tissues, including antigens that would otherwise be developmentally or spatially secluded from the immune system (18). A search of two independently derived public databases of global gene analysis using Affymetrix GeneChip arrays revealed that expression of $M y b 6$, encoding mouse $\alpha-M y H C$, was absent 
A

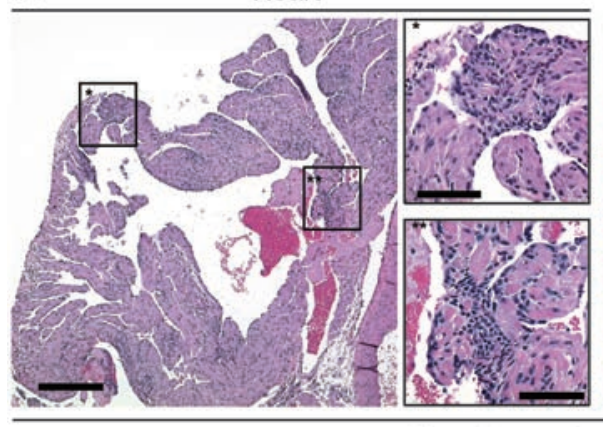

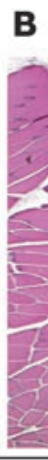

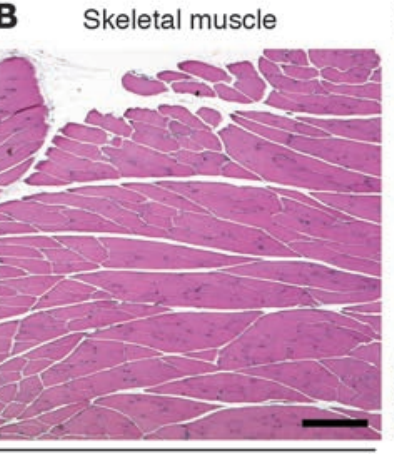

Clone E transfer
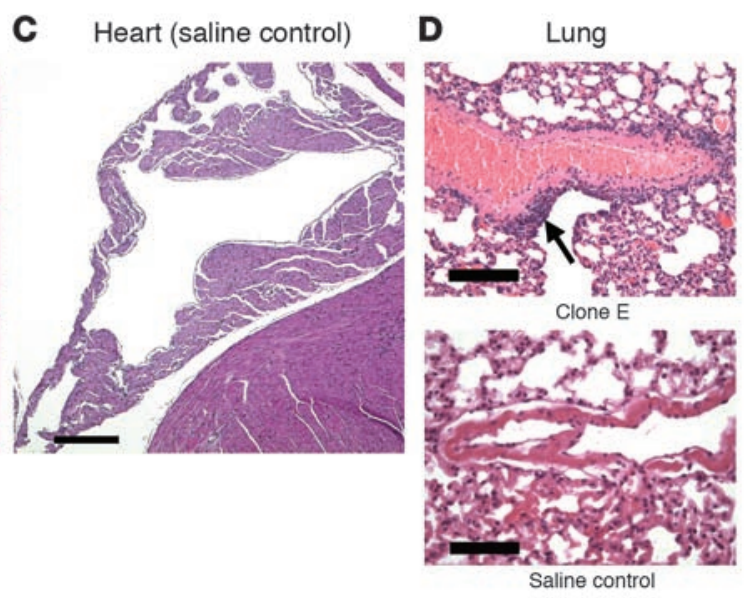

Figure 4

$\mathrm{CD}^{+} \mathrm{T}$ cell clones specific for $\alpha-\mathrm{MyHC}$ induce severe myocarditis when transferred into immunodeficient $\mathrm{DQ8}{ }^{+} \mathrm{Rag}{ }^{-/-N O D}$ mice. $(\mathbf{A})$ The host received $2.2 \times 10^{7}$ clone $E$ cells and was sacrificed 21 days later. H\&E staining revealed extensive lymphocytic infiltration of the heart with cardiac myocyte destruction (insets). In contrast, skeletal muscle (B) was devoid of infiltrates. Infiltrates were also observed around the $\alpha-\mathrm{MyHC}$-expressing cardiac muscle layer surrounding the pulmonary veins (D, arrow). Heart (C) and lungs (lower panel of $\mathbf{D})$ of saline control $\mathrm{DQ8}{ }^{+} \mathrm{Rag}^{-1-} \mathrm{NOD}$ mice that did not receive clone $\mathrm{E}$ are shown for comparison. The data are representative of 2 separate clone $\mathrm{E}$ transfers into $\mathrm{DQ8}^{+}$Rag $^{-/-N O D}$ recipients. Scale bars: $200 \mu \mathrm{m}$ in left panel of A, B, and C; $100 \mu \mathrm{m}$ in right panels of A; and $300 \mu \mathrm{m}$ in D.

or barely at detection limits in mTECs, whereas Myb7, encoding mouse $\beta$-MyHC, was clearly expressed (Figure 5A and Supplemental Table 1). These discordant expression patterns were surprising, since promiscuously expressed genes frequently colocalize in large chromosomal clusters spanning up to $1 \mathrm{Mb}$ (28), but Myb6 and $M y b 7$ are located in close proximity ( $\sim 4.5 \mathrm{~kb}$ apart) on the same chromosome (29). Since it can be difficult with microarray analyses to determine the presence or absence of gene expression at the very low end of the expression range, we performed RT-PCR analyses on cDNAs generated from purified thymic stromal subsets from DQ8 ${ }^{+}$NOD mice; WT NOD mice, which do not develop spontaneous myocarditis $(7,8)$ but are susceptible to post-viral myocarditis (11); and myocarditis-resistant C57BL/6 (B6) mice $(5,10)$. The purity of the subpopulations was confirmed by surface markers used for cell sorting (Supplemental Figure 5) and RT-PCR of indicator genes such as autoimmune regulator (Aire), cathepsins $S$ and $\mathrm{L}$, and known intrathymically expressed autoantigens (Figure $5 \mathrm{~A}$ ), and the specificity of amplification of $M y b 6$ and $M y b 7$ was confirmed with control tissues and cDNAs (Supplemental Figure 6). As expected, we readily detected transcripts encoding other cardiac proteins such as troponin I, troponin T, and $\beta$-MyHC in mTECs and other thymic cell subtypes. However, consistent with the microarray data, we were unable to detect $\alpha$-MyHC transcripts in whole thymus or purified thymic cell subsets from B6, NOD, or DQ8 ${ }^{+}$NOD mice (Figure 5A). Thus, both microarray and RT-PCR analyses showed that Myb6 was absent or expressed at very low levels in the thymus. These findings were confirmed by real-time PCR assays of mTECs (Figure 5B).

Recently, expression of a range of clinically relevant tissue-specific antigens has also been reported in lymph node stromal cells (LNSCs) and extrathymic Aire-expressing cells (eTACs), which can mediate potent $T$ cell deletional tolerance to antigens that are not expressed in the thymus (30-32). Remarkably, we found that $\alpha-\mathrm{MyHC}$ transcripts were not expressed in any of the 4 recently identified LNSC subsets, including fibroblastic reticular cells (FRCs, Fig- ure 5C) (33) and lymphatic endothelial cells (LECs) (34). It was also relevant to assess MyHC expression in eTACs, since they express a set of Aire-regulated tissue-specific genes that are non-overlapping with mTECs (30). But analysis of published microarrays (GEO GSE12388) showed that eTACs also did not express $\alpha$-MyHC but did express low levels of $\beta$-MyHC, similar to the patterns observed in mTECs (Figure 5A and Supplemental Table 2).

Reduced tolerance to cardiac myosin. To test whether the absence of $\alpha$-MyHC expression in thymus and peripheral lymphoid tissue correlated with impaired tolerance to cardiac myosin, we compared T cell responses of B6 and WT NOD mice in proliferative recall assays 9-10 days after immunization with mouse cardiac or soleus myosin in CFA. Analysis of the primed lymph node cells revealed markedly augmented $\mathrm{T}$ cell responsiveness to cardiac compared with soleus myosin in both strains, especially in NOD mice (Figure 5, D and E). However, the responses to soleus myosin, while attenuated, were not absent, consistent with the relatively modest levels of $\beta$-MyHC in mTECs (Figure 5A). Of note, paralleling these $T$ cell responses, we observed high-titer IgG antibody production (titers 1:400-1,600) to cardiac myosin in 6 of 6 NOD mice immunized with cardiac myosin. These autoantibodies also recognized soleus myosin, albeit at lower titers (1:100), reminiscent of the epitope spreading observed in DQ8 ${ }^{+}$NOD mice (Figure 1). In contrast, immunization with soleus myosin resulted in soleus myosin autoantibody positivity in only 1 of 6 mice, at low titers (1:100), consistent with findings in other mouse strains $(5,14)$. These responses were not associated with histological evidence of myocarditis (or skeletal muscle myositis) in WT NOD mice, but the 10-day immunization course may not have provided sufficient time for pathological changes to become manifest. As expected, immunized B6 mice did not develop autoantibodies to either cardiac or skeletal myosin $(5,14)$ (data not shown).

Prevention of myocarditis by expression of $\alpha-M y H C$ in thymus. We next sought to test whether the lack of thymic $\alpha$-MyHC expression contributes to the pathogenesis of myocarditis. The impor- 
A

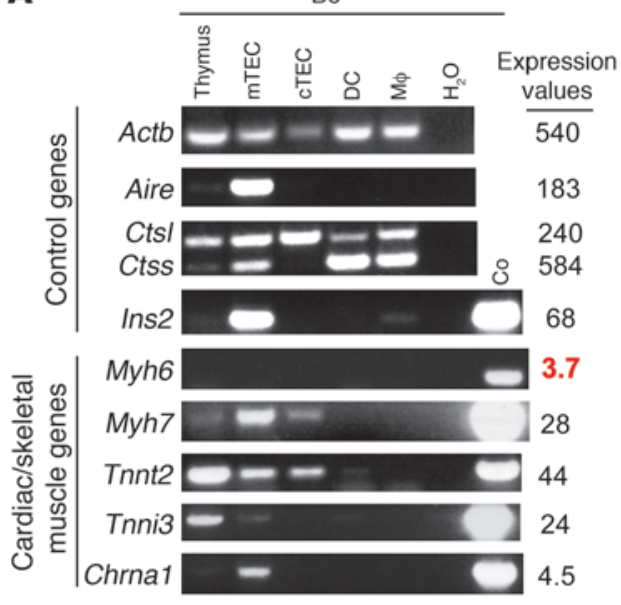

NOD

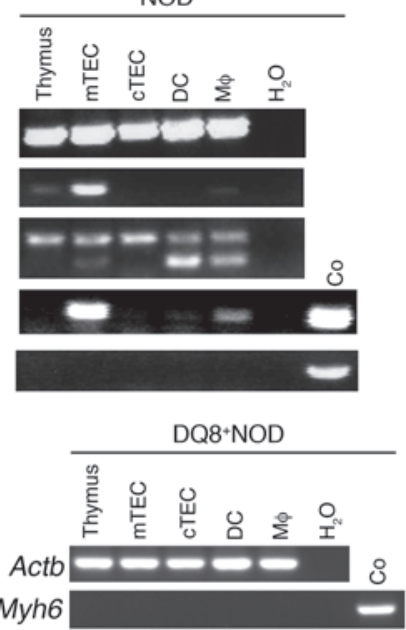

B

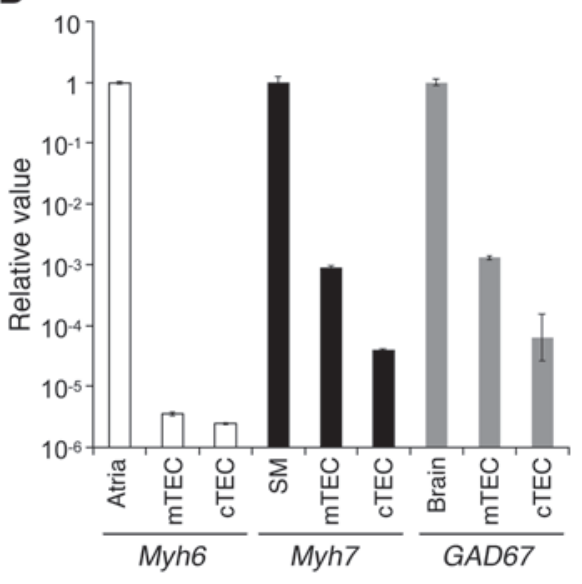

C

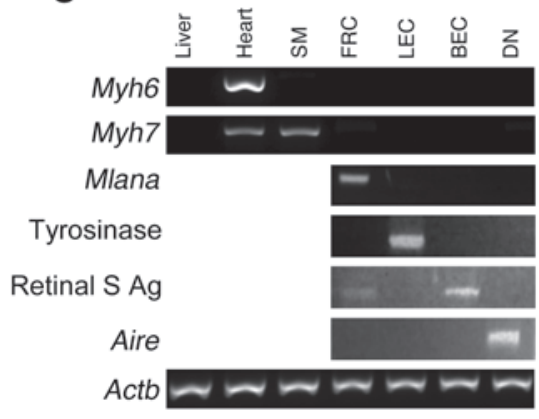

D

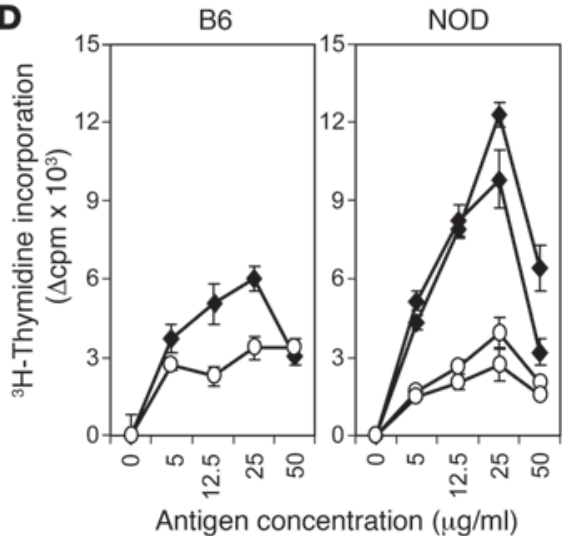

E

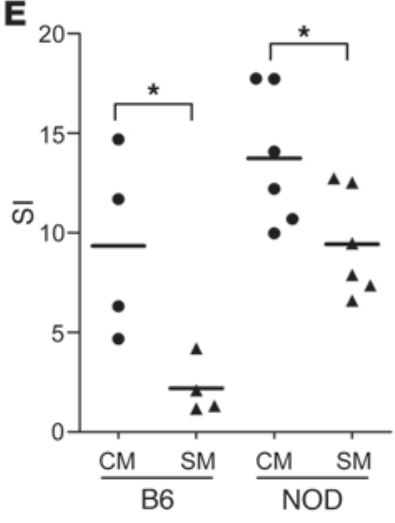

Figure 5

Lack of expression of $\alpha-M y H C$ in thymic and LNSC subsets is associated with reduced T cell tolerance to cardiac myosin. (A) Expression of control and tissue-restricted genes in whole thymus, purified mTECs, cTECs, DCs, and macrophages (M $\phi)$ from B6, NOD, and DQ8+NOD mice was determined by RT-PCR. Values represent microarray data (see Supplemental Table 1). Actb, $\beta$-actin; Ctsl, cathepsin L, Ctss, cathepsin S;

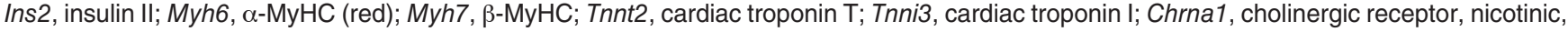
$\alpha$ polypeptide 1; Co, plasmid DNA as positive control. (B) Relative mRNA expression levels of Myh6, Myh7, and GAD67 were assessed by quantitative RT-PCR in purified mouse mTECs and cTECs and control tissues. Data were normalized to Actb. (C) Analysis of Myh6 and Myh7 expression in purified LNSC subsets: FRCs, LECs, BECs, and DN cells. Mlana, tyrosinase, retinal S antigen (Ag), and Aire are positive control genes for FRC, LEC, BEC, and DN subsets, respectively. (D) T cell tolerance to cardiac and soleus myosin as assessed by in vitro recall proliferative responses of representative B6 and NOD mice 10 days after immunization with cardiac myosin (filled diamonds), and soleus myosin (open circles). Data represent mean \pm SD of responses measured in triplicate. (E) Responses to indicated myosins in B6 and NOD mice as assessed by SI. Immunization and recall proliferation responses were performed as in D, and SI at $25 \mu \mathrm{g} / \mathrm{ml}$ antigen concentration was calculated as (counts - background counts/background counts) $\left({ }^{\star} P<0.05\right)$. The solid lines represent the mean values for each group.

tance of candidate autoantigens in organ-specific autoimmunity has traditionally been tested by the induction of tolerance though transgenic expression of self antigens via MHC class II promoters. However, this strategy typically results in the greatest expression in peripheral lymphoid organs, necessitating thymic transplantation and the production of bone marrow chimeras to prove the role of thymic self antigen expression in disease prevention (27). We therefore took a different approach, using a recently described Tet-Off transgenic system $(35,36)$ to specifically target $\alpha$-MyHC expression into the thymic epithelium of DQ8 $8^{+}$NOD mice. To this end, we first generated transgenic NOD mice carrying murine Myh6 cDNA (19) under the control of a TetO-CMV promoter (Figure $6 \mathrm{~A})$. These "TOM" reporter mice were then crossed with E $\alpha-\mathrm{tTA}$
("TA") driver NOD mice, in which the MHC class II promoterdriven TetR-VP16 transcriptional activator (tTA) is fortuitously expressed only in TECs, with little or no expression in dendritic cells, macrophages, or LNSCs (35). Analysis by Western blotting (Figure 6B) and TaqMan PCR (Figure 6C) revealed that recombinant $\alpha-\mathrm{MyHC}$ protein and transcripts were produced in thymus of $\mathrm{TOM}^{+} \mathrm{TA}^{+} \mathrm{NOD}$ mice, with very little or no expression in spleen, lymph node, or other tissues and expression dependent on the driver transgene (Figure $6 \mathrm{C}$ ). The $\mathrm{TOM}^{+} \mathrm{TA}^{+} \mathrm{NOD}$ transgenic lines were then bred into DQ8 ${ }^{+} \mathrm{NOD}$ mice to generate $\mathrm{TOM}^{+} \mathrm{TA}^{+} \mathrm{mII}^{-/-}$ $\mathrm{DQ}^{+}$NOD mice (hereafter, $\mathrm{TOM}^{+} \mathrm{TA}^{+} \mathrm{DQ} 8^{+} \mathrm{NOD}$ mice).

Approximately $73 \%$ (66 of 90 ) of DQ8 ${ }^{+}$NOD WT mice and $77 \%$ (17 of 22$)$ of $\mathrm{DQ}^{+} \mathrm{NOD}\left(\mathrm{TOM}^{+} \mathrm{TA}^{-} \mathrm{DQ}^{+}\right.$or $\left.\mathrm{TOM}^{-} \mathrm{TA}^{+} \mathrm{DQ}^{+}\right)$lit- 
A

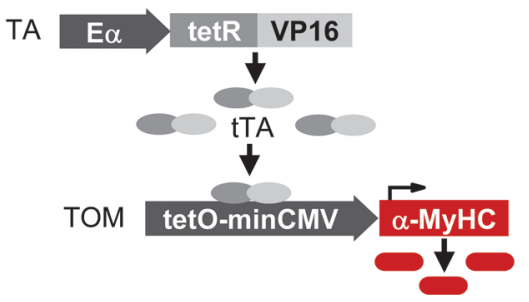

B

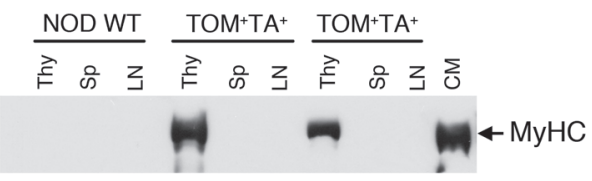

C

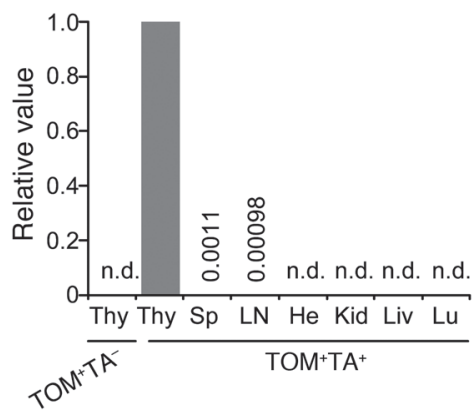

D

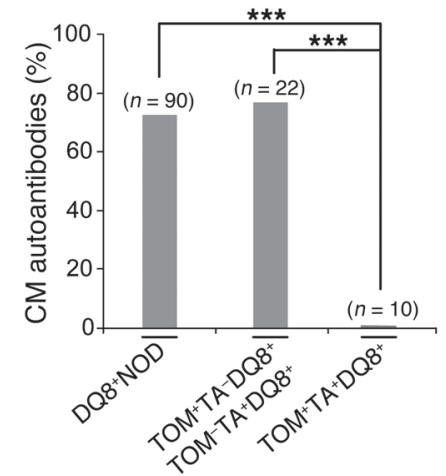

F

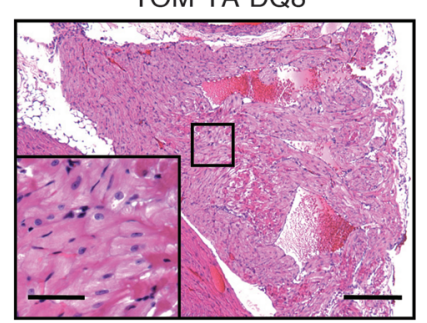

E

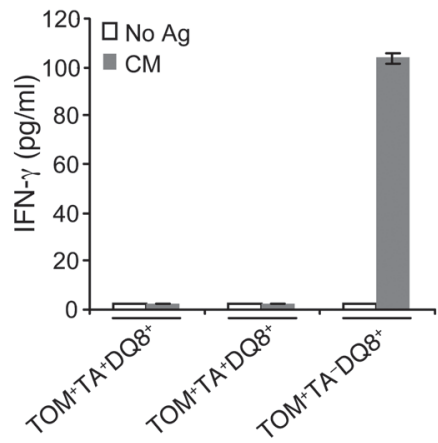

$\mathrm{TOM}^{-} \mathrm{TA}^{+} \mathrm{DQ} 8^{+}$

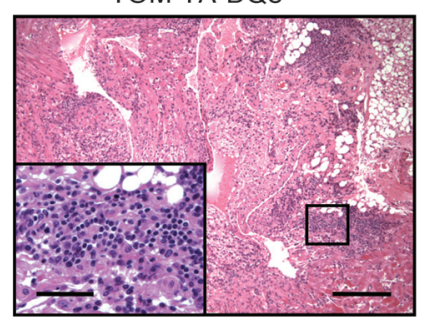

\section{Figure 6}

Expression of $\alpha-\mathrm{MyHC}$ in thymus prevents the development of myocarditis. (A) Schema of the transgenic strategy to target expression of $\alpha-\mathrm{MyHC}$ into thymic epithelium. (B) Western blot analysis of expression of $\alpha-\mathrm{MyHC}$ protein in thymic, splenic, and lymph node lysates from NOD WT and the indicated samples probed with a monoclonal antibody to MyHC. (C) TaqMan RT-PCR analysis of expression of transgenic $\alpha-M y H C$ transcripts in thymus (Thy), spleen (Sp), lymph node, heart (He), kidney (Kid), liver (Liv), and lung (Lu). Shown are the representative results of $3 \mathrm{TOM}^{+} \mathrm{TA}^{+}$mice; values are expressed relative to $\mathrm{TOM}^{+} \mathrm{TA}^{+}$thymus. n.d., not detected. (D) Prevalence of cardiac myosin autoantibodies in the indicated mice at 10 weeks of age $\left.{ }^{* * *} P<0.0001\right)$. (E) Comparison of IFN- $\gamma$ responses of splenic T cells to stimulation with cardiac myosin in 22- and 12-week-old TOM+TA+DQ8+ mice and a 12-week-old female littermate. Shown is the mean \pm SD of triplicate wells for each analysis. (F) H\&E staining of heart sections from a 19-week-old female TOM+TA+DQ8 ${ }^{+}$and a littermate. Original magnification, $\times 10$ and $\times 40$ (insets). Scale bars: $400 \mu \mathrm{m}$ and $100 \mu \mathrm{m}$ (insets).

termates developed myosin autoantibodies by 10 weeks of age (Figure 6D). In contrast, myosin autoantibodies were not detectable in $\mathrm{TOM}^{+} \mathrm{TA}^{+} \mathrm{DQ}^{+}$mice $(n=10 ; P<0.0001$, compared with either DQ8 ${ }^{+} \mathrm{NOD}$ WT mice or DQ8+ NOD littermates), suggesting $\mathrm{B}$ cell tolerance to cardiac myosin. Likewise, splenic T cells from $\mathrm{TOM}^{+} \mathrm{TA}^{+} \mathrm{DQ}^{+} \mathrm{NOD}$ mice $(n=4$ mice tested at age $12,19,20$, and 22 weeks) did not respond to stimulation with cardiac myosin (Figure 6E), but responded to anti-CD3 stimulation similarly to controls (Supplemental Figure 7). Furthermore, $\mathrm{TOM}^{+} \mathrm{TA}^{+} \mathrm{DQ}^{+}$ mice exhibited protection from myocarditis, with normal heart histology and no MNC infiltration (Figure 6F shows the histology of a heart from a 19 -week-old female $\mathrm{TOM}^{+} \mathrm{TA}^{+} \mathrm{DQ}^{+}$mouse and a $\mathrm{TOM}^{-} \mathrm{TA}^{+} \mathrm{DQ}^{+}$littermate). These results were similar for two independent $\mathrm{TOM}^{+}$founder lines (data not shown). Thus, induction of central tolerance to $\alpha$-MyHC prevented or significantly delayed the development of myocarditis in DQ8 ${ }^{+} \mathrm{NOD}$ mice.

Interestingly, in contrast to previous tolerance studies (27), T cell responses to cardiac myosin were detectable in $\mathrm{TOM}^{+} \mathrm{TA}^{+} \mathrm{DQ}^{+}$ mice after immunization of cardiac myosin in CFA. However, the magnitude of the responses was markedly reduced compared with responses in a $\mathrm{TOM}^{+} \mathrm{TA}^{-} \mathrm{DQ}^{+}$littermate (Supplemental Figure 8). Indeed, the amplitude of the responses was similar to the soleus myosin responses in soleus myosin-immunized $\mathrm{TOM}^{+} \mathrm{TA}^{-} \mathrm{DQ}^{+}$ and $\mathrm{TOM}^{+} \mathrm{TA}^{+} \mathrm{DQ}^{+}$mice. These results thus suggested that in the immunization setting, $\alpha-\mathrm{MyHC}-$ specific $\mathrm{T}$ cell responses in the thymic $\alpha$-MyHC-expressing $\mathrm{TOM}^{+} \mathrm{TA}^{+} \mathrm{DQ}^{+} \mathrm{NOD}$ mice were reduced to the levels of $\beta-\mathrm{MyHC}$ responses, but the responses to $\beta$-MyHC remained intact.

$\alpha-M y H C$ is also excluded from central tolerance induction in bumans. Given the high species conservation of tissue-specific antigen expression in the thymus $(18,37)$ but the inverse levels of $\alpha$ - and $\beta$-MyHC protein expression in mouse and human ventricle, it was of particular interest to examine whether the patterns of $\mathrm{MyHC}$ expression were conserved in mouse and human thymus. The range of expression levels was evaluated with the well-studied type 1 diabetes autoantigens GAD67 and GAD65 as positive and negative controls for human thymic tissue-specific antigen, respectively (ref. 37 and Figure 7A). These studies showed that MYH6, encoding human $\alpha-\mathrm{MyHC}$, was barely and sometimes not detectable in human mTECs and cortical thymic epithelial cells (cTECs), whereas expression of $M Y H 7$, encoding human $\beta$-MyHC, was clearly present, albeit at the low end of the normal range, closely mirroring the patterns of $M y b 7$ in mouse thymus (Figure 5, A and B). Thus, despite opposite expression levels of $\alpha$ - and $\beta$-MyHC in mouse and human heart, the thymic expression patterns were strictly conserved in both species. These data suggested that MYH6 was also a true "peripheral" autoantigen in humans. 

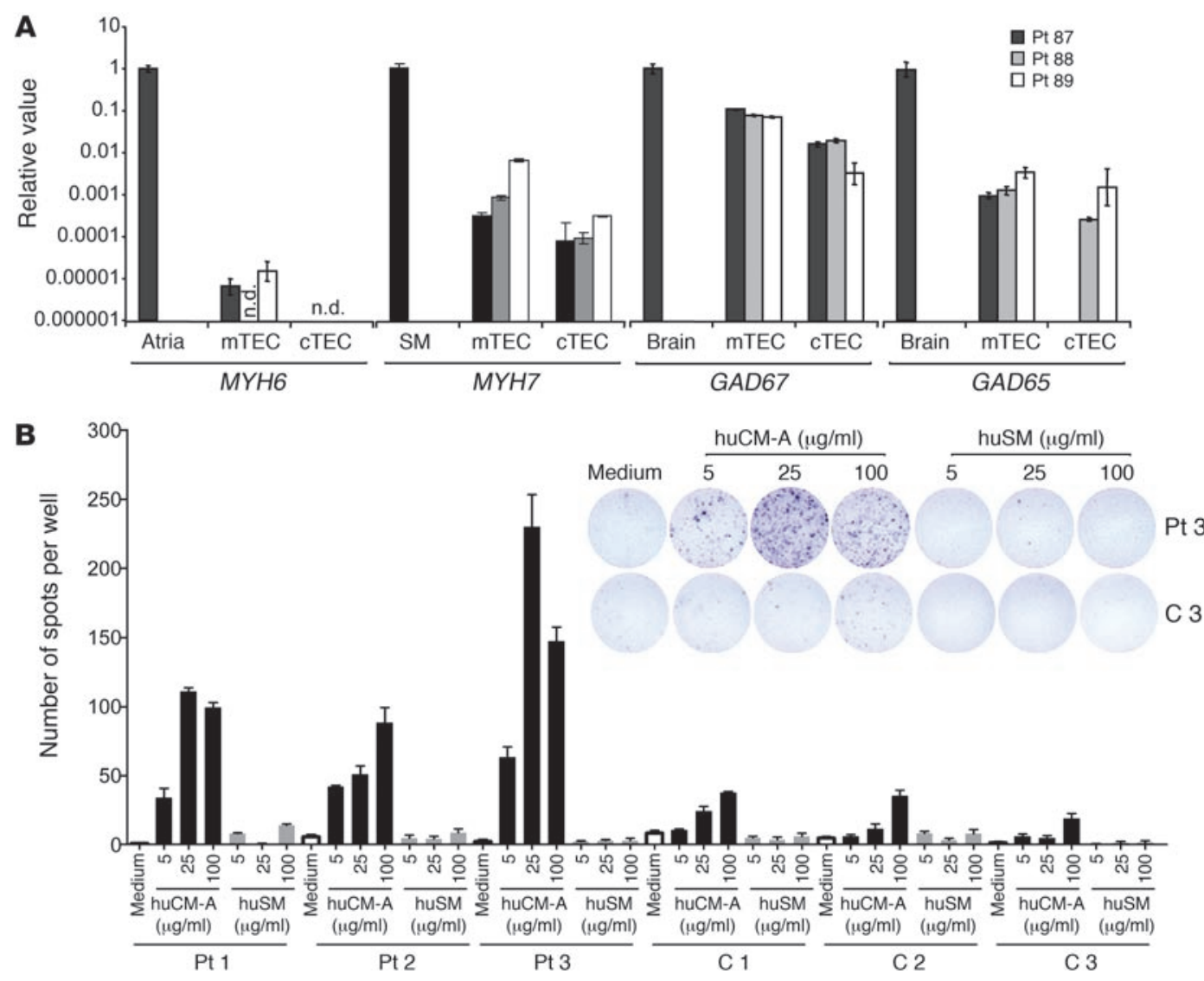

Figure 7

Lack of thymic expression of $\alpha-\mathrm{MyHC}$ (MYH6) is associated with impaired T cell tolerance to cardiac myosin in humans. (A) Relative expression levels of MYH6, MYH7, GAD65, and GAD67 were assessed by quantitative RT-PCR in purified human mTECs and cTECs and the respective control human tissues: heart atria, soleus muscle, and brain. Data from 3 human TEC samples are shown. Data were normalized to GAPDH, and relative expression was with respect to the control tissues. (B) IFN- $\gamma$ ELISPOT analyses indicate that human peripheral blood MNCs respond to huCM-A but not to huSM. The panels show, from left to right, the mean \pm SD of triplicate wells for each analysis on 3 patients with inflammatory heart disease (Pt 1: DR3, DR7; DQB1 ${ }^{*} 0201,{ }^{*} 0303$, Pt 2: DR4, DR16; DQB1 ${ }^{*} 0301,{ }^{*} 0502$, and Pt 3: DR3, DR4; DQB1 ${ }^{*} 0201,{ }^{*} 0302$ ) and 3 subjects without clinical heart disease (C 1: DR1, DR3; DQB*0501, *0201; C 2: DQB1*0503, *0301, and C 3: DR3, DR7; DQB*0202, *0201). Representative IFN- $\gamma$ responses of $\mathrm{Pt} 3$ and $\mathrm{C} 3$ are shown in the inset. Data in $\mathbf{A}$ and $\mathbf{B}$ are presented as mean \pm SD.

To investigate whether the lack of thymic expression of MYH6 correlated with enhanced $\mathrm{T}$ cell autoreactivity to $\alpha$-MyHC in human peripheral blood, we performed ex vivo IFN- $\gamma$ ELISPOT assays on fresh peripheral blood MNCs (26) from 3 patients with heart disease: Pt 1, a previously healthy 23 -year-old male who presented in cardiogenic shock due to severe Epstein-Barr viral myocarditis; Pt 2, an 18-year-old male with type 1 diabetes and chronic heart failure due to dilated cardiomyopathy, whose endomyocardial biopsy revealed evidence of myocarditis; Pt 3, a 24-year-old female with type 1 diabetes, Hashimoto thyroiditis, and unexplained cardiac dysfunction; two healthy control male subjects: $\mathrm{C} 1$ and C 2 (26 and 22 years old, respectively); and C 3, a 25-year-old male with type 1 diabetes but no clinical heart disease. While the magnitude of responses differed among these 6 individuals, the patterns were identical, with dose-dependent responses to huCM-A, whereas responses to huSM were similar to medium-alone (Figure $7 \mathrm{~B})$. Of note, healthy control subject $\mathrm{C} 1$ showed almost identical IFN- $\gamma$ responses to $\alpha$ - and $\beta-\mathrm{MyHC}$ in independent assays performed approximately 11 months apart (Supplemental Figure 9), demonstrating the reproducibility of these findings. Strikingly, all
3 patients with heart disease showed markedly elevated frequencies of $\alpha$-MyHC-specific T cells compared with the 3 control subjects without heart disease (Figure 7B). Since $\alpha-\mathrm{MyHC}$ constitutes only approximately $7 \%$ of total MyHC protein in healthy adult human heart, with even lower levels in diabetes (38) and heart failure (21), these findings underscore that the autoimmune targeting of $\alpha-\mathrm{MyHC}$ is primarily controlled by immunological tolerance mechanisms rather than by its abundance in heart.

\section{Discussion}

Our studies demonstrate that spontaneous myocarditis is initiated by immune responses directed against $\alpha-\mathrm{MyHC}$. We show that $\mathrm{CD}^{+} \mathrm{T}$ cell clones, along with bulk $\mathrm{T}$ cells from myocarditis lesions and peripheral lymphoid organs, predominantly recognize $\alpha$ - but not $\beta$-MyHC, consistent with the cardiac tissue specificity of this autoimmune disease process. We further show that $\alpha$-MyHC-specific Th $1 \mathrm{CD}^{+} \mathrm{T}$ cell clones transfer myocarditis into $\mathrm{DQ}^{+} \mathrm{Rag}^{-/} \mathrm{NOD}$ hosts, thus demonstrating that spontaneous myocarditis is caused by loss of $\mathrm{CD}^{+} \mathrm{T}$ cell tolerance to $\alpha$-MyHC. Transcripts for $\alpha$-MyHC were absent in both mouse and 
human mTECs, with markedly increased frequencies of circulating $\alpha-\mathrm{MyHC}-$ specific $\mathrm{CD} 4^{+} \mathrm{T}$ cells in mice and humans with myocarditis. Furthermore, we have shown that the transgenic expression of $\alpha-\mathrm{MyHC}$ in thymic epithelium induced tolerance to cardiac myosin and prevented the development of myocarditis in DQ8 ${ }^{+} \mathrm{NOD}$ mice. These results point to a previously unrecognized role for thymic tolerance in conferring susceptibility to autoimmune heart disease in both humans and mice.

It has been reported that $\mathrm{CD}^{+} \mathrm{T}$ cells are the major effector cells in myocarditis in DQ8 ${ }^{+} \mathrm{NOD}$ mice $(24,39)$. However, the antigen specificity of the pathogenic $\mathrm{CD} 4^{+} \mathrm{T}$ cells was not defined, and the $\mathrm{T}$ cell assays were performed with cardiac myosin isolated from porcine heart $(7,39)$, which predominantly expresses $\beta$-MyHC $(40)$, so that the contribution of reactivity to $\alpha-\mathrm{MyHC}$ was difficult to assess. In contrast to previous reports $(7,39)$, we have shown that autoimmune myocarditis in DQ8 ${ }^{+} \mathrm{NOD}$ mice is associated with the rapid intra- and intermolecular spreading of autoreactive $B$ cell responses. The use of highly purified antigens and longitudinal samples may have facilitated the early detection of epitope spreading in the current study. The early dissociation between the autoantigens targeted by $\mathrm{T}$ cells and autoantibodies highlights the key role of $\mathrm{T}$ cells in driving the cardiac specificity of this autoimmune disease process.

It is well established that thymic concentrations of tissue-specific antigens play a crucial role in susceptibility to organ-specific autoimmune diseases (18). For example, inherited promoter variants that decrease expression of insulin transcripts in thymus of humans (IDDM2) are strongly linked to T1D susceptibility $(41,42)$, and, conversely, thymic tolerance to transgenically overexpressed insulin in NOD mice dramatically reduces the incidence of diabetes (27). Likewise, a single nucleotide polymorphism in the promoter region of the $\alpha$-subunit of the muscle acetylcholine receptor, the pathogenic autoantigen of myasthenia gravis in humans, influences transcription levels of this receptor in thymus and correlates with the onset of disease (43). In transgenic mice with defined copy numbers of intrathymically expressed autoantigens, subtle differences in expression levels - in the range of 2- to 4-fold - significantly modulated susceptibility to autoimmunity (44). These and other studies have shown that all other variables being equal, individuals expressing self antigens at lower levels in the thymus are at higher risk for autoimmunity $(18,45)$. The demonstration that $\alpha-\mathrm{MyHC}$ expression was essentially absent in the thymus of both humans and mice, and furthermore that myocarditis was prevented by transgenic expression of $\alpha-\mathrm{MyHC}$ in the thymus, points to the contribution of impaired central tolerance in the pathogenesis of myocarditis.

The high frequency of cardiac myosin-specific $T$ cells in the normal immune repertoire suggests that active tolerance mechanisms in the periphery are essential for preventing ongoing myocarditis. While these immunoregulatory networks have not yet been defined, it is intriguing that $\alpha-\mathrm{MyHC}$ was also absent in LNSCs and eTACs, which mediate deletional tolerance to tissue-specific self antigens that are not expressed in the thymus (30-34). The heart is known to be richly endowed with tissue-resident dendritic cells (46) that can present cardiac-specific $\alpha$-MyHC peptides to cognate $\mathrm{CD}^{+} \mathrm{T}$ cells under steady-state conditions (47), suggesting the existence of alternative tolerogenic networks (48), presumably in the cardiac-draining lymph nodes. The striking phenotype of fatal autoimmune myocarditis associated with high-titer cardiac myosin autoantibodies in mice depleted of Tregs highlights the need for such mechanisms (49). It has been suggested that "natural" CD $25^{+}$Foxp $3^{+}$Tregs, the best-characterized mediators of tolerance so far, are generated on thymic epithelium $(50,51)$, and it will therefore be of considerable interest to define whether the observed protection from myocarditis in $\mathrm{TOM}^{+} \mathrm{TA}^{+} \mathrm{DQ}^{+}$mice is due to "recessive" (deletional) or "dominant" (via the generation of Tregs) tolerance.

While we demonstrate that thymic expression of $\alpha-\mathrm{MyHC}$ is sufficient to induce tolerance to cardiac myosin and protect from myocarditis, it should be noted that there are several other routes by which self antigens can access the thymus. It has been recently shown that about $50 \%$ of thymic DCs are immigrants, which may import and display self antigens from extrathymic sites (52). In one model system, migratory DCs carried a cardiac-specific neoantigen (mOVA) to thymus with deletion of cognate transgenic $\mathrm{CD}^{+} \mathrm{T}$ cells (53). However, ectopic thymic expression of mOVA transgene was not rigorously excluded by examination of purified stromal subsets (54). It is therefore unclear to what extent migratory DCs might complement the set of tissue-restricted antigens presented by TECs. However, there are other settings in which thymic expression of self antigen is not required for the induction of central tolerance $(32,55,56)$.

The lack of $\alpha-\mathrm{MyHC}$ in human thymus is consistent with our previous studies showing strong conservation in thymic expression of tissue-restricted self antigens between mice and humans (37). One implication of this "hole" in the thymic self antigen repertoire is that healthy individuals in the general population might be at increased risk for developing cardiac autoimmunity. Our findings may explain why the heart is so commonly targeted by autoimmunity in settings that promote the breakdown of peripheral tolerance. For example, up to $50 \%$ of people develop anti-myosin responses following acute myocardial infarction (57). While such reactions are transient and cease with infarct healing, our studies suggest that in autoimmune-prone patients, these reactions might become self-perpetuating and amplified, with pathological consequences.

In the absence of microbial triggers or pathological cardiac injury, what could trigger spontaneous myocarditis in DQ8 ${ }^{+} \mathrm{NOD}$ mice? While the initiating events of most autoimmune diseases are not fully understood, increasing evidence suggests that physiological or metabolic events that augment the presentation of self antigens can trigger $T$ cell autosensitization. In the case of autoimmune diabetes in NOD mice, particular attention has been directed to the period of pancreatic remodeling and the physiological "wave" of $\beta$ cell apoptosis observed at approximately 2 weeks of age that immediately precedes the onset of insulitis $(58,59)$. An analogous situation may be operative in the heart: shortly after birth, with the transition from fetal to neonatal circulation, there is a dramatic increase in workload, and the left ventricle undergoes profound physiological remodeling (60), with a switch from a predominant "fetal" $\beta$-MyHC to a predominant "adult" $\alpha$-MyHC expression (38). It thus seems plausible that during this perinatal period, high-avidity ("forbidden") $\alpha$-MyHC-specific T cells that have escaped thymic negative selection might become activated by the sudden exposure to large amounts $\alpha$-MyHC. It is interesting to note that in humans, the highest incidence of myocarditis and pediatric cardiomyopathy is in the first year of life $(2,61)$, suggesting parallel disease mechanisms in mice and humans.

The development of spontaneous myocarditis in DQ8 ${ }^{+} \mathrm{NOD}$ mice, but not in WT (I- $\left.\mathrm{A}^{\mathrm{g}}\right)$ NOD mice, underscores the important role for DQ8 in conferring susceptibility to this disease process. Of note, no differences were found in the percentages of 
$\mathrm{CD}^{+} \mathrm{CD} 25^{+} \mathrm{Foxp}^{+}$Tregs in spleen, lymph nodes, or peripheral blood between DQ8 ${ }^{+}$NOD and WT NOD mice to account for this differential disease susceptibility, although small decreases in the thymic Treg percentage were observed in DQ8 ${ }^{+} \mathrm{NOD}$ compared with NOD WT mice (Supplemental Figure 10). The lack of spontaneous myocarditis in WT NOD mice is surprising in view of the pronounced structural similarities in the antigen-binding pockets of the NOD I-Ag7 and human DQ8 MHC class II molecules (62), and the finding that the naturally processed peptides isolated from DQ8 and I-Ag7 molecules share sequence specificities $(63,64)$. However, while the peptide-binding specificities of DQ8 and $\mathrm{I}-\mathrm{A}^{\mathrm{g}}{ }^{7}$ are similar, they are not identical (64). We postulate that the differential myocarditis susceptibility may be explained by the preferential ability of DQ8 to present pathogenic epitopes of $\alpha-\mathrm{MyHC}$ that I-Ag7 does not present. Clarification of the molecular basis for spontaneous myocarditis susceptibility in DQ8 ${ }^{+} \mathrm{NOD}$ mice awaits the identification of the $\alpha-\mathrm{MyHC}$ epitope recognized by pathogenic DQ8-restricted $\mathrm{CD} 4^{+} \mathrm{T}$ cell clones.

The identification of key autoantigens and pathogenic pathways is a crucial step toward the development of specific intervention for autoimmune disease. Our data indicate that $\alpha-\mathrm{MyHC}$ is an important autoantigen in human myocarditis and that lack of thymic $\mathrm{CD}^{+} \mathrm{T}$ cell tolerance to $\alpha-\mathrm{MyHC}$ confers susceptibility to this serious condition. The low level of $\alpha-\mathrm{MyHC}$ protein in the normal human heart and even lower abundance in the failing human heart (21) may provide an explanation for the patchiness of lymphocytic infiltrates in myocarditis and the difficulties in diagnosing myocarditis by endomyocardial biopsy (65). Because even relatively subtle decreases in the amount of $\alpha-\mathrm{MyHC}$ expression can profoundly compromise cardiac function $(19,66,67)$, the development of pathogenic $\alpha$-MyHC-specific T cell infiltrates in the myocardium could pose particular challenges in humans. To date, most immunomodulatory strategies for myocarditis and idiopathic dilated cardiomyopathy have been directed against humoral autoimmunity (9). Our findings indicate that a more effective therapeutic approach would be to target autoreactive T cells.

\section{Methods}

Mice. Female NOD/LtJ (NOD) and C57BL/6J (B6) mice were purchased from the Jackson Laboratory. $\mathrm{C}^{-/-\mathrm{NOD}}$ and $\mu \mathrm{MT}^{-/-\mathrm{NOD}}$ mice were obtained from the Juvenile Diabetes Research Foundation International (JDRF) Center on Immunological Tolerance at Harvard Medical School. $\mathrm{TA}^{+} \mathrm{NOD}$ mice were the gift of Christophe Benoist (Department of Pathology, Harvard Medical School, Boston, Massachusetts, USA) (36). DQ8 ${ }^{+} \mathrm{mII}^{-/-}$ $\mathrm{NOD}\left(\mathrm{DQ} 8^{+} \mathrm{NOD}\right)$ and $\mathrm{DQ} 8^{+} \mathrm{mII}^{-/} \mathrm{Rag}^{-/-} \mathrm{NOD}\left(\mathrm{DQ} 8^{+} \mathrm{Rag}^{-/-} \mathrm{NOD}\right)$ mice were from our breeding colonies (8). Mouse protocols were approved by the Harvard Medical Area Standing Committee on Animals and the Joslin Diabetes Center Institutional Animal Care and Use Committee.

Human samples. Human thymus samples were obtained from Pt 87 (aged 4 months, female), Pt 88 (3 months, female), and Pt 89 (1 week, male) in the course of corrective cardiac surgery at the Department of Cardiac Surgery, Medical School of the University of Heidelberg. Normal human atria, ventricle, and soleus muscle tissues were obtained from the U.S. National Disease Research Interchange. Human PBMCs were obtained from type 1 diabetic patients and healthy control subjects from the Joslin Diabetes Center. Human studies were approved by the Ethics Committee of the Medical School of the University of Heidelberg, the Joslin Diabetes Center Committee on Human Studies (protocols 04-34 and 04-12), and Partner's Human Research (protocol 2004p-000084). Written informed consent was received prior to inclusion in the studies.
Antigens. Myosins were purified from heart and soleus muscle from Rag ${ }^{-1}$ NOD mice and from human ventricle, atria, and soleus muscle as described previously (8). Purified mouse cardiac troponin I and cardiac troponin $\mathrm{T}$ were purchased from Life Diagnostics Inc.

Western blotting. Immunoblot analyses were performed as described previously (8). In brief, $0.25 \mu \mathrm{g} /$ lane each of purified mouse or human myosin, $\mathrm{cTnI} / \mathrm{cTnT}, 1 \mu \mathrm{g}$ total heart extract were separated on $10 \%$ SDS gels and transferred to nitrocellulose, and the blots were subsequently incubated with serial sera from DQ8 ${ }^{+} \mathrm{NOD}$ mice at 1:5,000 dilution, followed by incubation with peroxidase-labeled $\mathrm{F}(\mathrm{ab})_{2}$ fragment of goat-anti mouse IgG (Jackson ImmunoResearch Laboratories Inc.). Blots were developed using Western Lightning Chemiluminescence Reagent Plus (PerkinElmer).

Isolation of T cell clones from $D Q 8^{+} \mathrm{NOD}$ myocarditic hearts. Hearts were cannulated and perfused according to the Langendorff method (Alliance for Cellular Signaling [AfCS] Procedure Protocol PP00000125). Single-cell suspensions were prepared by pipetting tissue pieces and staining with anti-CD4 and - $\mathrm{CD} 3 \mathrm{mAbs}$ (BD Biosciences - Pharmingen). $\mathrm{CD}_{4}^{+} \mathrm{CD}^{+}$cells were single-cell sorted (MoFlo, Cytomation) into individual wells of a 96-well roundbottom plate containing $1 \times 10^{5}$ irradiated (50 Gy) DQ8 ${ }^{+} \mathrm{NOD}$ splenocytes as feeder cells in RPMI containing 20\% FBS, IL-2, IL-7 (both at $10 \mathrm{U} / \mathrm{ml}$; Peprotech), $100 \mathrm{U} / \mathrm{ml}$ penicillin, $100 \mu \mathrm{g} / \mathrm{ml}$ streptomycin, $2 \mathrm{mM}$ glutamine, $50 \mu \mathrm{M} 2$-mercaptoethanol, and $2.5 \mu \mathrm{g} / \mathrm{ml}$ ConA (Calbiochem). Clones were grown at $37^{\circ} \mathrm{C}$ in $5 \% \mathrm{CO}_{2}$ and re-expanded every $10-14$ days.

Adoptive transfer of clone $E$. One week after restimulation with ConA and APCs, clone E cells were harvested by removing ConA with $\alpha$-methyl-Dmannopyranoside (10 mg/ml; Sigma-Aldrich). Clone E was purified on a Ficoll-Hypaque density gradient (GE Healthcare) before i.v. injection into $\mathrm{DQ8}^{+} \mathrm{Rag}^{-/}$NOD recipients.

Histology. Tissues were fixed in Bouin's solution (Sigma-Aldrich), embedded in paraffin, and stained for H\&E as previously described (8).

ELISA. Approximately $1 \times 10^{6} \mathrm{MNCs}$ isolated from hearts, cardiac draining LNs, or spleens of myocarditic mice were plated in duplicate in round-bottom 96-well plates in supplemented AIM-V media (Invitrogen) containing the indicated antigen and incubated at $37^{\circ} \mathrm{C}$ for 96 hours. Supernatants from various conditions were tested in duplicate wells for IFN- $\gamma$ concentration with a Mouse IFN- $\gamma$ "Femto-HS" High Sensitivity ELISA Kit (eBioscience).

Intracellular cytokine staining of heart-infiltrating Tcells. Hearts from DQ8 ${ }^{+} \mathrm{NOD}$ mice were perfused with $20 \mathrm{ml}$ PBS containing $2 \%$ heparin, followed by the same volume of PBS containing $0.2 \mathrm{mg} / \mathrm{ml}$ collagenase type IV (Worthington). Hearts were minced and dissociated into single cells by 3 sequential 15 -minute incubations at $37^{\circ} \mathrm{C}$, with slow stirring, in a buffer mix containing $0.2 \mathrm{mg} / \mathrm{ml}$ each of collagenase type II, collagenase type IV, and dispase and $0.025 \mathrm{mg} / \mathrm{ml}$ DNase I (Sigma-Aldrich) in RPMI medium. Heart MNCs were separated from cardiomyocytes on a discontinuous Percoll (GE Healthcare) gradient at densities of $1.04 \mathrm{~g} / \mathrm{ml}$ and $1.09 \mathrm{~g} / \mathrm{ml}$, followed by centrifugation at $600 \mathrm{~g}$ for 25 minutes. The heart MNCs were pulsed in supplemented AIM-V containing $10 \mathrm{ng} / \mathrm{ml}$ PMA and $500 \mathrm{ng} / \mathrm{ml}$ ionomycin (Sigma-Aldrich) at $37^{\circ} \mathrm{C}$ for 4 hours, with $10 \mu \mathrm{g} / \mathrm{ml}$ brefeldin $\mathrm{A}$ added in the last 2 hours. Heart MNCs were surface stained with anti-TCR $\beta$, -CD4, and -CD8 antibodies after FcR blockade, fixed and permeabilized. Intracellular staining was done with anti-IFN- $\gamma$, -IL-4, -TNF- $\alpha$, and -IL-17 antibodies (BD Biosciences - Pharmingen). Flow cytometric data were acquired on an LSR II instrument (BD) and analyzed with FlowJo software (Tree Star).

$m T E C$ and eTAC microarray data. Gene expression microarray data of mTECs were obtained from the Joslin Diabetes Center ImmGen v2.003 (GEO GSE85) and the German Cancer Research Center Heidelberg (GEO GSE2585), both available at http://www.ncbi.nlm.nih.gov/geo. Gene expression raw microarray data for B6/129 mTECs from GSE85 were processed using the RMA probe-level normalization algorithm. Gene expression 
microarray data of eTACs was obtained from the NCBI Gene Expression Omnibus repository (GSE12388) (30).

Purification of thymic stromal cells. Thymic stromal cells were purified as described previously $(28,37)$. In brief, after enzymatic digestion, TECs were pre-enriched using anti-CD45 MicroBeads and the autoMACS Pro separator (Miltenyi Biotec). The pre-enriched fraction was stained with purified 2.4G2 and biotinylated G8.8 mAbs, followed by PE-CDR1, APC-Cy7CD45, FITC-CD11c, APC-CD11b, and PE-Cy7-steptavidin. Cortical TECs (CD45 $5^{-/ \mathrm{lo}} \mathrm{CDR} 1^{+} \mathrm{G} 8.8^{+}$), mTECs (CD45-/lo $\mathrm{CDR} 1^{-} \mathrm{G} 8.8^{+}$), macrophages $\left(\mathrm{CD} 45^{+/ h i} \mathrm{CD} 11 \mathrm{~b}^{\text {bright }} \mathrm{CD} 11 \mathrm{c}^{\text {lo }}\right)$, and DCs $\left(\mathrm{CD} 45^{+/ h i} \mathrm{CD} 11 \mathrm{~b}^{\text {lo }} \mathrm{CD} 11 \mathrm{c}^{\text {hi }}\right)$ were sorted on a Cytomation MoFlo or BD FACSAria cell sorter.

Preparation of LNSC subsets. LNSC subsets were prepared as described previously (33) from 6-10 male B6 mice at 4-6 weeks of age. In brief, cells were then enriched for CD45- stroma using CD45 MicroBeads (Miltenyi Biotec). Enriched stroma were stained and sorted to high purity (>95\%) using a FACSAria. Antibodies used were CD45 (clone 40-F11, BD), gp38 (clone 8.1.1, Developmental Studies Hybridoma Bank), and CD31 (clone MEC13.3, BioLegend). After gating on $\mathrm{CD}^{-} 5^{-}$stroma, subsets were sorted as follows: FRCs, gp $38^{+} \mathrm{CD} 31^{-}$; LECs, gp $38^{+} \mathrm{CD} 31^{+}$; blood endothelial cells (BECs), gp38-CD31+' and double negative (DN) cells, gp38-CD31- Sorted cells were snap frozen in RLT buffer (QIAGEN) and stored at $-80^{\circ} \mathrm{C}$.

RNA preparation and cDNA synthesis. Mouse RNA from whole tissues or $50 \times 10^{3}$ to $200 \times 10^{3}$ sorted thymic cells was isolated with TRIzol (Invitrogen), according to the manufacturer's protocol. Total mRNA (typically $\sim 800 \mathrm{ng}$ ) from sorted cell populations was amplified once with the MessageAmp aRNA Kit (Ambion). Total amplified RNA $(\sim 5 \mu \mathrm{g})$ was reverse transcribed into cDNA with oligo(dT) $)_{12-20}$ primer and Omniscript Reverse Transcriptase (QIAGEN). Human tissue RNA was isolated using the RNeasy Mini Kit (QIAGEN) and DNase I. RNA from human single-cell suspension was isolated with the High Pure RNA Isolation Kit (Roche). Total human RNA was reverse transcribed into cDNA with Oligo(dT) ${ }_{20}$ Primer and Superscript II Reverse Transcriptase (Invitrogen), followed by RNase H digestion (Fermentas). Prior to PCR analysis, the cDNA solution was purified using MicroSpin G-50 columns (Amersham) according to the manufacturer's instructions. LNSC RNA extraction and cDNA synthesis were performed using the RNeasy Micro Kit (QIAGEN) and SuperScript III First-Strand Synthesis System (Invitrogen), according to the manufacturers' protocols.

RT-PCR analysis. PCRs were done in a final volume of $50 \mu \mathrm{l}$, with $1.25 \mathrm{U}$ HotStarTaq DNA Polymerase (QIAGEN). Final concentrations of the PCR mix were $1 \mu \mathrm{M}$ for each primer and $250 \mu \mathrm{M}$ dNTP PCR buffer containing $1.5 \mathrm{mM} \mathrm{MgCl}_{2}$ and Q-Solution. Amplification was carried out under the following conditions: a single denaturing step at $95^{\circ} \mathrm{C}$ for 15 minutes for all genes, except for $\mathrm{Myb} 6$ at $95^{\circ} \mathrm{C}$ for 1 minute, followed by 40 cycles (promiscuously expressed genes), 30 cycles (positive control genes), or 25 cycles ( $\beta$-actin) of $94^{\circ} \mathrm{C}$ for 30 seconds to 1 minute, $50-68^{\circ} \mathrm{C}$ for 1 minute, and $68^{\circ} \mathrm{C}$ for 1 minute for $\mathrm{Myh} 6$ and $M y b 7$, or $72^{\circ} \mathrm{C}$ for 1 minute for control genes; this was followed by a final extension step of $68^{\circ} \mathrm{C}$ for 10 minutes for $M y b 6$ and $M y b 7$ or $72^{\circ} \mathrm{C}$ for 10 minutes for control genes. The following intron-spanning primer pairs were used (sense and antisense respectively): mouse Myh6, 5'-GCTACACTCTTCTCTACC-3' and 5'-CATAGAGAATGCGGTTGG-3'; mouse Myh7, 5' ${ }^{\prime}$-TGCCAACTATGCTGGAGC-3' and 5'-CACTGGATAATCAGCAGG-3'. Positive control cDNAs encoding murine Myh6 and Myh7 were a gift from J. Robbins (19) (Cincinnati Children's Hospital, Cincinnati, Ohio, USA). The following additional intronspanning primer pairs were used (sense and antisense, respectively): $\beta$-actin, $5^{\prime}$-TGGAATCCTGTGGCATCCATGAAAC- $3^{\prime}$ and $5^{\prime}$-TAAAACGCAGCTCAGTAACAGTCCG-3'; Aire, 5'-CAGCAGGTGTTTGAGTCAGG-3' and 5'-ACAGCCGTCACAACAGATGA-3'; cathepsin L, 5'-AAAGGGTTGTGTGACTCC- $3^{\prime}$ and $5^{\prime}$-TCTTGCTGCTACAGTTGG- $3^{\prime}$; cathepsin S, 5' -ACATGACCGAAGCTTTCC-3' and $5^{\prime}$-CATCAAGAGTCCCATAGC-3'; insulin II,
5'-AGCCCTAAGTGATCCGC-3' and 5'-TCTCCAGCTGGTAGAGGG-3'; Ach R $\alpha, 5^{\prime}$-ATGACGGCTCTGTGGTGG-3' and $5^{\prime}$-CGGTGGTGTGTGTTGATGAC-3'; cardiac troponin T2, 5'-CGACCACCTGAATGAAGACC-3 and 5'-TTCTAGCTAAGCCAGCTCCC-3'; cardiac troponin I, 5'-TCCGATCCTGTTCTCTGCCTCTGG- $3^{\prime}$ and $5^{\prime}$-CACAGTGTGGGAGCCATGGC-3'.

Quantitative PCR analysis. Real-time PCR reactions were set up in a final volume of $25 \mu \mathrm{l}$ with optimal concentrations of the forward and reverse primers (50-900 nM) using iTaq SYBR Green Supermix with ROX (BioRad). The reactions were run on a sequence detection system (GeneAmp 7300, Applied Biosystems) using the standard cycling conditions and melting curve analysis. Expression values were normalized to either mouse $\beta$-actin or human GAPDH expression using the comparative Ct method. The following primer pairs were used (sense and antisense, respectively): mouse Myh6, 5'-AACCAGAGTTTGAGTGACAGAATG-3' and 5'-ACTCCGTGCGGATGTCAA-3'; mouse Myh7, 5'-GCGACTCAAAAAGAAGGACTTTG-3' and 5'-GGCTTGCTCATCCTCAATCC-3'; mouse GAD67, 5'-GGTTCGCACAGGTCACCC-3' and 5'-GCCATTCACCAGCTAAACCAA- $3^{\prime}$; mouse $\beta$-actin, $5^{\prime}$-ACGGCCAGGTCATCACTATTG- $3^{\prime}$ and $5^{\prime}$-AGGATTCCATACCCAAGAAGGAA- $3^{\prime}$; human MYH6, 5'-TTCTCCGTGAAGGGATAACC-3' and 5'-CGTCTTCCCATTCTCGGTTTCAGC-3'; human MYH7, 5'-GGCCCCTTTCCTCATCTGTAG-3' and 5'-CGGTCACTGTCTTGCCATACTCAG-3'; human GAD65, 5'-GCAATTAAAACAGGGCATCCTAGA- $3^{\prime}$ and $5^{\prime}$-ATGTTAGTATTTGCTGTT-

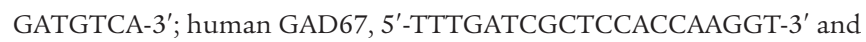
5'-TCCAAGTTGAAGCCCTCCAT-3'; human GAPDH, 5' -TCGACAGTCAGCCGCATCT- $3^{\prime}$ and $5^{\prime}$-CCGTTGACTCCGACCTTCA-3'.

Immunization and recall responses. NOD or B6 mice (6-8 weeks old) were immunized with $300 \mu \mathrm{g}$ of mouse cardiac or soleus myosin emulsified in CFA. Draining popliteal lymph node cells were isolated 8-10 days later and cultured in 96-well plates $\left(5 \times 10^{5}\right.$ cells/well $)$ in supplemented AIM-V media alone or with media containing titrated concentrations of antigens. Proliferation assays were performed as described previously (68).

Generation of $\mathrm{TOM}^{+} \mathrm{TA}^{+}$transgenic NOD mice. The TOM construct contains the Myh6 cDNA (19) (positions 2-5,871) cloned into the Sall site of the tetO-SB plasmid (36) after linkers were used to introduce novel PacI sites into the AatII and Eco47III sites. The transgene expression cassette was excised by digestion with PacI, purified as previously described (8), and microinjected into fertilized NOD oocytes (JDRF Center for Immunological Tolerance). Progeny were screened by PCR assays with a primer set spanning tetO-SB and Myh6 (sense: 5'-TCTGCATATAAATTCTGGCTGGCG-3' and antisense: $5^{\prime}$-TTTCCGCAGTGACTTTGCCC-3'). TOM-positive founders were crossed with TA+NOD mice (36). The TA-controlled and tissuerestricted expression of TOM was determined by TaqMan RT-PCR with cDNA samples from various tissues from $\mathrm{TOM}^{+} \mathrm{TA}^{+}$and $\mathrm{TOM}^{+} \mathrm{TA}^{-}$mice, using sense primer $5^{\prime}$-TGAGAACTTCAGGCTCC- 3 ', antisense primer 5'-GCTGCTGCCCCGAAGTC-3', and the probe FAM-5'-AGAATTCGTCGACAGAAT-3'-Tamra. Tightly restricted lines were selected to be crossed with DQ8 ${ }^{+} \mathrm{NOD}$ mice, and primer sets for TOM, TA, DQ8, and murine MHC class II (8) were used for genotyping.

ELISPOT assay. Fresh human PBMCs were isolated on density gradients from anti-coagulated human whole blood samples essentially as described previously (26). PBMCs were adjusted to $2 \times 10^{6} / \mathrm{ml}$ in $15 \mathrm{ml}$ polypropylene tubes in $0.5 \mathrm{ml}$ complete HL-1 medium supplemented with $10 \%$ human $\mathrm{AB}$ serum (Gemini Biotech) and stimulated for 42 hours with the indicated antigens. 96-well plates (Nunc Maxisorp) were precoated with $4 \mu \mathrm{g} / \mathrm{ml}$ anti-human IFN- $\gamma$ (Endogen) in PBS overnight at $4^{\circ} \mathrm{C}$, washed with PBS, and blocked for 1 hour at $37^{\circ} \mathrm{C}$ with PBS/1\% BSA. Each sample was washed and resuspended in $0.6 \mathrm{ml}$ complete HL-1 medium and approximately $3 \times 10^{5}$ cells $/ 100 \mu \mathrm{l}$ were dispensed in triplicate into wells of the ELISPOT plates. After 16 hours incubation, ELISPOT plates were 
washed, and $2 \mu \mathrm{g} / \mathrm{ml}$ biotinylated anti-human IFN- $\gamma$ antibody was added to each well and incubated for 2 hours at $37^{\circ} \mathrm{C}$. Plates were washed, and alkaline phosphatase-conjugated streptavidin was added to each well and incubated for 2 hours at $37^{\circ} \mathrm{C}$. The plates were washed, and NBT solution was added to each well for 45 seconds at room temperature. The reactions were stopped by washing the plates under tap water. Spots were counted using an automated immunospot reader (Cellular Technology Ltd.). For clone E cells, ELISPOT assay was performed as above, except that clone E cells $\left(1 \times 10^{4}\right.$ cells/well $)$ and irradiated DQ8 ${ }^{+}$NOD splenocytes $\left(5 \times 10^{5}\right.$ cells/well) were incubated directly in ELISPOT plates precoated with $5 \mu \mathrm{g} / \mathrm{ml}$ anti-mouse IFN- $\gamma$ or IL- 4 capture antibody at $37^{\circ} \mathrm{C}$ for 72 hours in AIM-V media supplemented with $50 \mu \mathrm{M} 2$-mercaptoethanol containing the indicated antigens.

Statistics. Data were analyzed using Excel (Microsoft) and Prism (GraphPad) software. An unpaired 2-tailed Student's $t$ test was applied. $P$ values less than 0.05 were considered significant.

\section{Acknowledgments}

We thank Jeffrey Robbins, Mohamed Sayegh, and Diane Mathis for valuable reagents; Mark Anderson, James Gardner, Bechara Mfarrej, Mireia Guerau-de-Arellano, Emily Venanzi, and Aldo Rossini for helpful discussions; John Stockton for microinjections; Heather Thomas for expert technical support; Howard Wolpert and Susan Anello for patient recruitment; Panagiota Stamou for her initial contributions to this project; and the National Disease Research Interchange for human heart and soleus muscle samples. This work was supported by NIH grants R01 DK072090, HL077554 (to M.A. Lipes), DK074500, and P01 AI045757 (to S.J. Turley), JDRF grant 33-2008-394 (to M.A. Lipes), and the Joslin Diabetes Center Diabetes and Endocrinology Research Center (DERC). B. Kyewski and S. Pinto have been supported by the German Cancer Research Center, the European Union-funded Consortia Thymaide (grant 503410) and Immunotherapy (grant 14363), and the Deutsche Forschungsgemeinschaft (SFB 405).

Received for publication July 30, 2010, and accepted in revised form January 19, 2011.

Address correspondence to: Myra A. Lipes, One Joslin Place, Rm. 373, Joslin Diabetes Center, Boston, Massachusetts 02215, USA. Phone: 617.309.2624; Fax: 617.309.2639; E-mail: myra.lipes@ joslin.harvard.edu.
1. Lipshultz SE, et al. The incidence of pediatric cardiomyopathy in two regions of the United States. N Engl J Med. 2003;348(17):1647-1655.

2. Nugent AW, et al. The epidemiology of childhood cardiomyopathy in Australia. N Engl J Med. 2003;348(17):1639-1646.

3. Rose NR, Baughman KL. Myocarditis and dilated cardiomyopathy. In: Rose NR, Mackay IR, eds. The Autoimmune Diseases. Boston, Massachusetts, USA: Academic Press; 2006:875-888.

4. Strauss A, Lock JE. Pediatric cardiomyopathy - a long way to go. NEngl J Med. 2003;348(17):1703-1705.

5. Neu N, Rose NR, Beisel KW, Herskowitz A, GurriGlass G, Craig SW. Cardiac myosin induces myocarditis in genetically predisposed mice.J Immunol. 1987;139(11):3630-3636.

6. Smith SC, Allen PM. Myosin-induced acute myocarditis is a T cell-mediated disease. J Immunol. 1991;147(7):2141-2147.

7. Elliott JF, et al. Autoimmune cardiomyopathy and heart block develop spontaneously in HLA-DQ8 transgenic IAbeta knockout NOD mice. Proc Natl Acad Sci U S A. 2003;100(23):13447-13452.

8. Taylor JA, Havari E, McInerney MF, Bronson R, Wucherpfennig KW, Lipes MA. A spontaneous model for autoimmune myocarditis using the human MHC molecule HLA-DQ8. J Immunol. 2004; 172(4):2651-2658

9. Lappe JM, Pelfrey CM, Tang WH. Recent insights into the role of autoimmunity in idiopathic dilated cardiomyopathy. J Card Fail. 2008;14(6):521-530.

10. Neu N, Beisel KW, Traystman MD, Rose NR, Craig SW. Autoantibodies specific for the cardiac myosin isoform are found in mice susceptible to Coxsackievirus B3-induced myocarditis. J Immunol. 1987; 138(8):2488-2492.

11. Horwitz MS, La Cava A, Fine C, Rodriguez E, Ilic A, Sarvetnick N. Pancreatic expression of interferongamma protects mice from lethal coxsackievirus B3 infection and subsequent myocarditis. Nat Med.2000; 6(6):693-697.

12. Weiss A, Leinwand LA. The mammalian myosin heavy chain gene family. Annu Rev Cell Dev Biol. 1996; 12:417-439.

13. Donermeyer DL, Beisel KW, Allen PM, Smith SC. Myocarditis-inducing epitope of myosin binds constitutively and stably to I-Ak on antigen-presenting cells in the heart. J Exp Med. 1995;182(5):1291-1300.

14. Pummerer CL, et al. Identification of cardiac myosin peptides capable of inducing autoimmune myocarditis in BALB/c mice. J Clin Invest. 1996; 97(9):2057-2062.

15. Rose NR. Viral damage or 'molecular mimicry' placing the blame in myocarditis. Nat Med. 2000; 6(6):631-632.

16. Stewart GC, et al. Myocardial parvovirus B19 persistence: lack of association with clinicopathologic phenotype in adults with heart failure. Circ Heart Fail. 2011;4(1):71-78.

17. Frustaci A, Russo MA, Chimenti C. Randomized study on the efficacy of immunosuppressive therapy in patients with virus-negative inflammatory cardiomyopathy: the TIMIC study. Eur Heart J. 2009; 30(16): 1995-2002.

18. Kyewski B, Klein L. A central role for central tolerance. Annu Rev Immunol. 2006;24:571-606.

19. Krenz M, et al. Analysis of myosin heavy chain functionality in the heart. J Biol Chem. 2003; 278(19):17466-17474.

20. Giger JM, Haddad F, Qin AX, Baldwin KM. In vivo regulation of the beta-myosin heavy chain gene in soleus muscle of suspended and weight-bearing rats. Am J Physiol Cell Physiol. 2000;278(6):C1153-C1161.

21. Miyata S, Minobe W, Bristow MR, Leinwand LA. Myosin heavy chain isoform expression in the failing and nonfailing human heart. Circ Res. 2000; 86(4):386-390.

22. Kurabayashi M, Tsuchimochi H, Komuro I, Takaku F, Yazaki Y. Molecular cloning and characterization of human cardiac alpha- and beta-form myosin heavy chain complementary DNA clones. Regulation of expression during development and pressure overload in human atrium. J Clin Invest. 1988; 82(2):524-531.

23. Yang M, Charlton B, Gautam AM. Development of insulitis and diabetes in B cell-deficient NOD mice. J Autoimmun. 1997;10(3):257-260.

24. Hayward SL, Bautista-Lopez N, Suzuki K, Atrazhev A, Dickie P, Elliott JF. CD4 T cells play major effector role and CD8 T cells initiating role in spontaneous autoimmune myocarditis of HLA-DQ8 transgenic IAb knockout nonobese diabetic mice. J Immunol. 2006;176(12):7715-7725.

25. Jones WK, Sanchez A, Robbins J. Murine pulmonary myocardium: developmental analysis of cardiac gene expression. Dev Dyn. 1994;200(2):117-128.

26. Arif S, et al. Autoreactive T cell responses show proinflammatory polarization in diabetes but a regulatory phenotype in health. J Clin Invest. 2004; 113(3):451-463.
27. Jaeckel E, Lipes MA, Von Boehmer H. Recessive tolerance to preproinsulin 2 reduces but does not abolish type 1 diabetes. Nat Immunol. 2004; 5(10):1028-1035

28. Derbinski J, et al. Promiscuous gene expression in thymic epithelial cells is regulated at multiple levels. J Exp Med. 2005;202(1):33-45.

29. Mahdavi V, Chambers AP, Nadal-Ginard B. Cardiac alpha- and beta-myosin heavy chain genes are organized in tandem. Proc Natl Acad Sci U S A. 1984; 81(9):2626-2630.

30. Gardner JM, et al. Deletional tolerance mediated by extrathymic Aire-expressing cells. Science. 2008;321(5890):843-847.

31. Lee JW, et al. Peripheral antigen display by lymph node stroma promotes $\mathrm{T}$ cell tolerance to intestinal self. Nat Immunol. 2007;8(2):181-190.

32. Nichols LA, Chen Y, Colella TA, Bennett CL, Clausen BE, Engelhard VH. Deletional self-tolerance to a melanocyte/melanoma antigen derived from tyrosinase is mediated by a radio-resistant cell in peripheral and mesenteric lymph nodes. J Immunol. 2007; 179(2):993-1003.

33. Fletcher AL, et al. Lymph node fibroblastic reticular cells directly present peripheral tissue antigen under steady-state and inflammatory conditions. J Exp Med. 2010;207(4):689-697.

34. Cohen JN, et al. Lymph node-resident lymphatic endothelial cells mediate peripheral tolerance via Aire-independent direct antigen presentation. J Exp Med. 2010;207(4):681-688.

35. Guerau-de-Arellano M, Martinic M, Benoist C, Mathis D. Neonatal tolerance revisited: a perinatal window for Aire control of autoimmunity. J Exp Med. 2009;206(6):1245-1252.

36. Witherden D, van Oers N, Waltzinger C, Weiss A Benoist C, Mathis D. Tetracycline-controllable selection of CD4(+) T cells: half-life and survival signals in the absence of major histocompatibility complex class II molecules. J Exp Med. 2000;191(2):355-364.

37. Gotter J, Brors B, Hergenhahn M, Kyewski B. Medullary epithelial cells of the human thymus express a highly diverse selection of tissue-specific genes colocalized in chromosomal clusters. J Exp Med. 2004; 199(2):155-166

38. Haddad F, Bodell PW, Qin AX, Giger JM, Baldwin $\mathrm{KM}$. Role of antisense RNA in coordinating cardiac myosin heavy chain gene switching. J Biol Chem. 2003;278(39):37132-37138.

39. Taneja $\mathrm{V}$, et al. Spontaneous myocarditis mimicking 
human disease occurs in the presence of an appropriate MHC and non-MHC background in transgenic mice. J Mol Cell Cardiol. 2007;42(6):1054-1064

40. Lompre AM, et al. Species- and age-dependent changes in the relative amounts of cardiac myosin isoenzymes in mammals. Dev Biol. 1981;84(2):286-290.

41. Pugliese A, et al. The insulin gene is transcribed in the human thymus and transcription levels correlated with allelic variation at the INS VNTRIDDM2 susceptibility locus for type 1 diabetes. Nat Genet. 1997;15(3):293-297.

42. Vafiadis $P$, et al. Insulin expression in human thymus is modulated by INS VNTR alleles at the IDDM2 locus. Nat Genet. 1997;15(3):289-292.

43. Giraud M, et al. An IRF8-binding promoter variant and AIRE control CHRNA1 promiscuous expression in thymus. Nature. 2007;448(7156):934-937.

44. Liston A, et al. Gene dosage-limiting role of Aire in thymic expression, clonal deletion, and organ-specific autoimmunity. J Exp Med. 2004;200(8):1015-1026.

45. Liston A, Lesage S, Gray DH, Boyd RL, Goodnow CC. Genetic lesions in T-cell tolerance and thresholds for autoimmunity. Immunol Rev. 2005;204:87-101.

46. Hart DN, Fabre JW. Demonstration and characterization of Ia-positive dendritic cells in the interstitial connective tissues of rat heart and other tissues, but not brain. J Exp Med. 1981;154(2):347-361.

47. Smith SC, Allen PM. Expression of myosin-class II major histocompatibility complexes in the normal myocardium occurs before induction of autoimmune myocarditis. Proc Natl Acad Sci U S A. 1992;89(19):9131-9135.

48. Steinman RM, Hawiger D, Nussenzweig MC. Tolerogenic dendritic cells. Annu Rev Immunol. 2003 21:685-711.

49. Ono M, Shimizu J, Miyachi Y, Sakaguchi S. Control of autoimmune myocarditis and multiorgan inflammation by glucocorticoid-induced TNF receptor fam- ily-related protein(high), Foxp3-expressing CD25+ and CD25- regulatory T cells. J Immunol. 2006; 176(8):4748-4756.

50. Aschenbrenner K, et al. Selection of Foxp3+ regulatory $\mathrm{T}$ cells specific for self antigen expressed and presented by Aire+ medullary thymic epithelial cells. Nat Immunol. 2007;8(4):351-358.

51. Bensinger SJ, Bandeira A, Jordan MS, Caton AJ, Laufer TM. Major histocompatibility complex class II-positive cortical epithelium mediates the selection of CD4(+)25(+) immunoregulatory T cells. J Exp Med. 2001;194(4):427-438.

52. Derbinski J, Kyewski B. How thymic antigen presenting cells sample the body's self-antigens. Curr Opin Immunol. 2010;22(5):592-600.

53. Bonasio R, Scimone ML, Schaerli P, Grabie N, Lichtman AH, von Andrian UH. Clonal deletion of thymocytes by circulating dendritic cells homing to the thymus. Nat Immunol. 2006;7(10):1092-1100.

54. Grabie N, et al. IL-12 is required for differentiation of pathogenic CD8 $+\mathrm{T}$ cell effectors that cause myocarditis. J Clin Invest. 2003;111(5):671-680.

55. Allen S, et al. Promiscuous thymic expression of an autoantigen gene does not result in negative selection of pathogenic T cells. J Immunol. 2005; 175(9):5759-5764.

56. Huseby ES, Sather B, Huseby PG, Goverman J. Agedependent $\mathrm{T}$ cell tolerance and autoimmunity to myelin basic protein. Immunity. 2001;14(4):471-481.

57. Elahi AW, Vijayakumar AN, Lichstein E, Mokhtarian F. Interplay of antibody and $\mathrm{T}$ cell responses in acute myocardial infarction. J Lab Clin Med. 2001; 138(2):112-118.

58. Trudeau JD, Dutz JP, Arany E, Hill DJ, Fieldus WE, Finegood DT. Neonatal beta-cell apoptosis: a trigger for autoimmune diabetes? Diabetes. 2000;49(1):1-7.

59. Turley S, Poirot L, Hattori M, Benoist C, Mathis D. Physiological \{beta\} cell death triggers priming of self-reactive $T$ cells by dendritic cells in a type- 1 diabetes model. J Exp Med. 2003;198(10):1527-1537.

60. Webb GD, Smallhorn JF, Therrien J, Redington AN. Congenital heart disease. In: Zipes DP, Libby P, Bonow RO, Braunwald E, eds. Braunwald's Heart Disease. Philadelphia, Pennsylvania, USA: Elsevier Saunders; 2005:1489-1552.

61. Andrews RE, Fenton MJ, Ridout DA, Burch M. Newonset heart failure due to heart muscle disease in childhood: a prospective study in the United kingdom and Ireland. Circulation. 2008;117(1):79-84.

62. Lee K, Wucherpfennig K, Wiley D. Structure of a human insulin peptide-HLA-DQ8 complex and susceptibility to type 1 diabetes. Nat Immunol. 2001; 2(6):501-507.

63. Suri A, Walters JJ, Gross ML, Unanue ER. Natural peptides selected by diabetogenic DQ8 and murine I-A molecules show common sequence specificity. J Clin Invest. 2005;115(8):2268-2276.

64. Yu B, Gauthier L, Hausmann DH, Wucherpfennig $\mathrm{KW}$. Binding of conserved islet peptides by human and murine MHC class II molecules associated with susceptibility to type I diabetes. Eur I Immunol. 2000; 30(9):2497-2506

65. Baughman KL. Diagnosis of myocarditis: death of Dallas criteria. Circulation. 2006;113(4):593-595.

66. Abraham WT, et al. Coordinate changes in Myosin heavy chain isoform gene expression are selectively associated with alterations in dilated cardiomyopathy phenotype. Mol Med. 2002;8(11):750-760.

67. van Rooij E, Sutherland LB, Qi X, Richardson JA, Hill J, Olson EN. Control of stress-dependent cardiac growth and gene expression by a microRNA. Science. 2007;316(5824):575-579.

68. Havari E, et al. Expression of the B7.1 costimulatory molecule on pancreatic beta cells abrogates the requirement for CD4 $\mathrm{T}$ cells in the development of type 1 diabetes. J Immunol. 2004;173(2):787-796. 